\title{
MHD Effects on Ciliary-Induced Peristaltic Flow Coatings with Rheological Hybrid Nanofluid
}

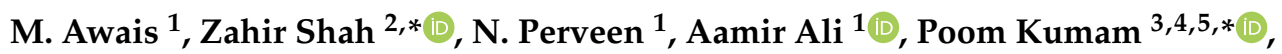 \\ Habib ur Rehman ${ }^{3}$ and Phatiphat Thounthong ${ }^{6}$ (i)
}

1 Department of Mathematics, COMSATS University Islamabad, Attock Campus, Kamra Road, Attock 43600, Pakistan; awais@ciit-attock.edu.pk (M.A.); Nabeela.mpa@gmail.com (N.P.); aamir_ali@cuiatk.edu.pk (A.A.)

2 Center of Excellence in Theoretical and Computational Science (TaCS-CoE), SCL 802 Fixed Point Laboratory, Science Laboratory Building, King Mongkut's University of Technology Thonburi (KMUTT), 126 Pracha-Uthit Road, Bang Mod, ThrungKhru, Bangkok 10140, Thailand

3 Department of Mathematics, King Mongkut's University of Technology Thonburi (KMUTT), 126 PrachaUthit Rd., Ban Mod, Thung Khru, Bangkok 10140, Thailand; hrehman.hed@gmail.com

4 KMUTT-Fixed Point Theory and Applications Research Group, Theoretical and Computational Science Center (TaCS), Science Laboratory Building, Faculty of Science, King Mongkut's University of Technology Thonburi (KMUTT), 126 Pracha-Uthit Road, Bang Mod, ThrungKhru, Bangkok 10140, Thailand

5 Department of Medical Research, China Medical University Hospital, China Medical University, Taichung 40402, Taiwan

6 Renewable Energy Research Centre, Department of Teacher Training in Electrical Engineering, Faculty of Technical Education, King Mongkut's University of Technology North Bangkok, 1518 Pracharat 1 Road, Bangsue, Bangkok 10800, Thailand; phatiphat.t@fte.kmutnb.ac.th

* Correspondence: zahir.sha@kmutt.ac.th (Z.S.); poom.kum@kmutt.ac.th (P.K.)

Received: 27 November 2019; Accepted: 12 February 2020; Published: 19 February 2020

check for updates

\begin{abstract}
Present theoretical investigation is a mathematical illustration of an application to endoscopy by incorporating hybrid nanoparticles and an induced magnetic field with a rheological fluid model for more realistic results. Rheological fluid behavior is characterized by the Ostwald-de-Waele power-law model. A hybrid nanofluid mechanism is considered comprising platelet-shaped nanoparticles since nanoparticles are potential drug transportation tools in biomedical applications. Moreover, ciliary activity is encountered regarding their extensive applications in performing complex functions along with buoyancy effects. An endoscope is inserted inside a ciliated tube and peristalsis occurred due to ciliary activity in the gap between tube and endoscope. A non-Newtonian model is developed by mathematical formulation which is tackled analytically using homotopy analysis. The outcomes are interpreted graphically along with the pressure rise and streamlining configuration for the case of negligible inertial forces and long wavelength. A three-dimensional graphical interpretation of axial velocity is studied as well. Moreover, tables are prepared and displayed for a more physical insight.
\end{abstract}

Keywords: hybrid nanofluid; induced magnetic field; mixed convection; heat generation; peristalsis; cilia beating; Non-Newtonian

\section{Introduction}

Fluids possess a significant role in the amplification of heat exchange rate in numerous engineering systems, e.g., heat exchangers, oil and petrochemical industries. Nanoparticle suspensions, pioneered by Choi [1], made thermal performance of these fluids more effective and it has become a topic of interest for many investigators [2-5]. Regardless of researchers' efforts, there has been an elementary issue with mono nanofluids that either they possess better thermal association or good rheological characteristics. For example, metal oxides such as $\mathrm{Al}_{2} \mathrm{O}_{3}$ show excellent chemical inertness as well as 
stability, whereas metallic nanoparticles including $\mathrm{Al}$ and Ag exhibit better thermal conductivities. Most of the authentic applications required transaction between different properties of nanofluids and thus hybridization of nanomaterials has been introduced. Hybrid nanofluids can be manufactured by dispersing nanoparticles of different materials individually or a mixture of nanoparticles in base fluid. For instance, impacts of $\mathrm{Cu}-\mathrm{Ag}$ nanohybrids on velocity and thermal boundary layer transport inside the wedge have been investigated by Hassan et al. [6]. To gain the highest composite thermal conductivity, chemical inertness and stability by using a small-volume fraction of nanoparticles at lower production cost is the motivation of researchers behind their utilization of hybrid nanofluids [7-10]. Moreover, nanoparticles of $\mathrm{TiO}_{2}$ exhibit antibacterial and photocatalytic properties. Nguyen et al. [11] has studied antibacterial properties of $\mathrm{TiO}_{2}$ by adopting silver decorative technique and revealed that oxide nanoparticles of titanium did not show inhibitory impacts for bacteria whereas silver loaded $\mathrm{TiO}_{2}$ nanocomposites display efficient antibacterial characteristics at a concentration of $40 \mathrm{mg} / \mathrm{mL}$. Ag nanoparticles are able to devastate pathogenic bacteria under ultraviolet radiation for efficient degradation of toxic pollutants as well as being easy to attach to cell membranes [12-14]. Therefore, $\mathrm{Ag}-\mathrm{TiO}_{2}$ nanocomposite is preferred in this theoretical inspection. Moreover, platelet-shaped particles are chosen since they capacitate swift healing in skin injuries because of their innate capability to make a boundary intended for vascular walls.

A cilium is a microscopic, contractile, thin fiber-like slender appendage/protrusion that projects from surfaces of specific cells. In the adult human body, epithelial cells along with motile cilia are very prominent in specific brain sections. Due to their motility, they possess a considerable role in many physiological processes like locomotion, alimentation and respiration. Peristalsis is a spontaneous process of a symmetrical wave's expansion and contraction within flexible boundaries. Ciliary-induced peristalsis appears significantly in various biological transport processes such as in biomedicine, physiology and nuclear reactors. Recently, Awais et al. [15] examined second-law analysis for peristaltic nanofluid flow caused by ciliary action with magnetic effects. Furthermore, they studied convective peristalsis of viscous fluid by considering non-uniform viscosity [16] as well. Furthermore, the concept of peristaltic pumps, instigated by Engelman [17], has latterly been prominent in several biological functions including roller pumps and heart-lung machines etc. As peristalsis is a cutting-edge field due to physiological applications, several theoretical as well as experimental attempts have been made to incorporate nanoparticles in order to improve thermal performance in biomedical processes. Rashidi et al. [18] exemplified the application of MHD peristaltic transport of blood containing nanoparticles in drug delivery through an incompatible channel which is practically imperative in the bio-sciences. Hayat et al. [19] explicated mixed convective heat transfer in the peristalsis of nanoparticles suspended in water assuming convective boundary conditions and joule heating. Recently, Maqbool et al. [20] inspected the impacts of nanoparticles on magnetohydrodynamic tangent hyperbolic fluid transportation in a ciliated tube.

Attention to non-Newtonian fluids arises as the majority of the physiological fluids possess non-Newtonian behavior verified by experimental observations. In view of the fact that simplified Newtonian models yield somewhat ambiguous results, several investigations on rheological fluid behaviors have been carried out to obtain more realistic results. Examples include inelastic fluid models e.g., the power-law model and viscoelastic fluid models such as the Johnson-Segalman model, Oldroyd-B model and Maxwell model. Mixed convection impacts towards peristaltic transport of magnetohydrodynamic non-Newtonian nanofluid were numerically evaluated by Hayat et al. [21]. The current study examines the rheological nature of fluid by employing Ostwald-de-Waele power law model, a generalized one, in which rheological nature directly depends on power law index $n$ and deals with the shear thinning for $(n<1)$ and shear thickening for $(n>1)$ behaviors of fluid [22-25].

Moreover, the peristaltic flow with influences of applied magnetic field led to significant applications in biomedical engineering problems [26-28]. In the case of large magnetic Reynolds number for an electrically conducting fluid, induction becomes more prominent than magnetic diffusion, and this made the induced magnetic field effects accountable. Shit et al. [29] examined the influence 
of induced magnetic field on peristalsis of a micropolar fluid assuming velocity slip. They observed that peristaltic flow rate enlarges in an induced magnetic field which led to mechanical stimulation. So, magnetic induction is appropriate in cancer treatment and magneto therapy as predicted in literature [30-32]. Besides this, the performance of coatings with magnetic nanoparticles and heat transport is ever-present in various fields. Magnetic nanoparticles, approved by the FDA (Food and Drug Administration) [33], with coating are applicable in medical processes such as blood pressure control of a patient, pharmacotherapy, surgery and alcohol detoxification etc. Ellahi et al. [34] carried out a comparative investigation on shiny film coating on multi-fluids dispersed by nanoparticles. Akbar and Butt [35] inspected the physiological flow of Casson fluid through a plumb duct. They observed that fluid behaves as electrically conducting with a uniform magnetic field and found analytical results under small wave number and low-Reynolds number approximations. The recent related research can be read in [36-38].

Furthermore, endoscopic imaging is a precious diagnostic instrumental locating persistent access to tissues deep inside hollow organs of the body. A conventional white-light endoscope is a solid circular cylinder placed in a peristaltic tube. Fluid flow occurs in the space between the tube and endoscope, and then further diagnostic procedures can be made such as for bleeding, cancerous growths and precancerous polyps. Hayat et al. [39] have addressed the peristaltic transport of the MHD power law fluid with endoscope effects. Hayat and Ali [40] have inspected the impact of an endoscope on peristaltically induced flow of micropolar fluid. The influences of non-uniform viscosity on peristaltic motion of Newtonian fluid through an endoscope have been conducted by Akbar and Nadeem [41]. Rathod and Asha [42] have investigated endoscope effects along with a magnetic field on peristalsis of the Newtonian fluid. They concluded that stress formation in a curved structure wall augments as compared to straight walls. In view of the significance of research regarding endoscopy applications, various studies have made (see refs. [43-48]).

With several advantages, advanced endoscopes are deficient in the spatial resolution for detection and treatment of cancers and abnormalities at small scales. Ciliary walls have importance since these biological cilia are helpful to perform complex biomimetic functions and applicable in vitro and in vivo synthetic organs as well as drug-delivery applications. In these unmet requirements, the effects of hybrid nanofluid and induced magnetic field on endoscopy application inside a ciliated peristaltic tube are addressed. Mathematical modeling is performed by considering negligible inertial forces and small wave number. An analytical solution of governing model is carried out by the homotopy analysis method, and results are plotted physically against several sundry parameters via tables and graphs. The trapping phenomenon is examined with the effects of electromagnetic induction as well.

\section{Problem Description}

A non-linear problem, concerning the transport and heat-transfer characteristics of non-Newtonian $\left(\mathrm{Ag}-\mathrm{TiO}_{2} / \mathrm{H}_{2} \mathrm{O}\right)$ hybrid nanofluid in an endoscope due to ciliary metachronical rhythm is investigated here. A cylindrical coordinate system is used with $(R, \theta, Z)$ as position coordinates of fluid particles. Non-Newtonian behavior of the flow is considered with Ostwald-de-Waele power law model expressed as [22,25]:

$$
\tau=-k\left\{\sqrt{\left|\frac{1}{2} \Delta: \Delta\right|^{n-1}}\right\} \Delta .
$$

where,

$$
\frac{1}{2} \Delta: \Delta=2\left(\left(\frac{\partial U}{\partial R}\right)^{2}+\left(\frac{U}{R}\right)^{2}+\left(\frac{\partial W}{\partial Z}\right)^{2}\right)+\left(\frac{\partial W}{\partial R}+\frac{\partial U}{\partial Z}\right)^{2}
$$

In above expression $k$ and $\mathrm{n}$ respectively represents flow consistency index and power law index. In this study, non-Newtonian shear thickening fluid is considered with $n=2$. Moreover, a constant magnetic field having intensity $\mathrm{H}_{0}$ is taken in radial direction causes an induced magnetic field $\mathrm{H}^{\prime}\left(\mathrm{H}_{\mathrm{r}}(\mathrm{r}, \mathrm{z}), 0, \mathrm{H}_{\mathrm{z}}(\mathrm{r}, \mathrm{z})\right)$ and, thereby, total magnetic field vector is $\mathrm{H}\left(\mathrm{H}_{0}+\mathrm{H}_{\mathrm{r}}(\mathrm{r}, \mathrm{z}), 0, \mathrm{H}_{\mathrm{z}}(\mathrm{r}, \mathrm{z})\right)$. 
The governing system of equations in an unsteady form is $[25,29,30]$ :

$$
\begin{aligned}
& \frac{\partial \mathrm{U}}{\partial \mathrm{R}}+\frac{\mathrm{U}}{\mathrm{R}}+\frac{\partial \mathrm{W}}{\partial \mathrm{Z}}=0 \\
& \frac{\partial \mathrm{U}}{\partial \mathrm{t}}+\mathrm{U} \frac{\partial \mathrm{U}}{\partial \mathrm{R}}+\mathrm{W} \frac{\partial \mathrm{U}}{\partial \mathrm{Z}}=\frac{-1}{\rho_{\mathrm{hnf}}} \frac{\partial \mathrm{P}}{\partial \mathrm{R}}-\frac{1}{\rho_{\mathrm{hnf}}}\left(\frac{1}{\mathrm{R}} \frac{\partial\left(2 \mathrm{kR} \Phi \frac{\partial \mathrm{U}}{\partial \mathrm{R}}\right)}{\partial \mathrm{R}}+\frac{\partial\left(\mathrm{k} \Phi\left(\frac{\partial \mathrm{U}}{\partial \mathrm{Z}}+\frac{\partial \mathrm{W}}{\partial \mathrm{R}}\right)\right)}{\partial \mathrm{Z}}\right)-\frac{\hat{\mu}}{2 \rho_{\mathrm{hnf}}}\left(\frac{\partial \mathrm{H}^{2}}{\partial \mathrm{R}}\right)+ \\
& \frac{\hat{\mu}}{\rho_{\text {hnf }}}\left(\frac{\partial \mathrm{H}_{\mathrm{r}}}{\partial \mathrm{t}}+\left(\mathrm{H}_{0}+\mathrm{H}_{\mathrm{r}}\right) \frac{\partial \mathrm{H}_{\mathrm{r}}}{\partial \mathrm{R}}+\mathrm{H}_{\mathrm{z}} \frac{\partial \mathrm{H}_{\mathrm{r}}}{\partial \mathrm{Z}}\right), \\
& \frac{\partial \mathrm{W}}{\partial \mathrm{t}}+\mathrm{U} \frac{\partial \mathrm{W}}{\partial \mathrm{R}}+\mathrm{W} \frac{\partial \mathrm{W}}{\partial \mathrm{Z}}=\frac{-1}{\rho_{\mathrm{hnf}}} \frac{\partial \mathrm{P}}{\partial \mathrm{Z}}-\frac{1}{\rho_{\mathrm{hnf}}}\left(\frac{1}{\mathrm{R}} \frac{\partial\left(\mathrm{k} \Phi \mathrm{R}\left(\frac{\partial \mathrm{U}}{\partial \mathrm{Z}}+\frac{\partial \mathrm{W}}{\partial \mathrm{R}}\right)\right)}{\partial \mathrm{R}}+\frac{\partial\left(2 \mathrm{k} \Phi \frac{\partial \mathrm{W}}{\partial \mathrm{Z}}\right)}{\partial \mathrm{Z}}\right)-\frac{\hat{\mu}}{2 \rho_{\mathrm{hnf}}}\left(\frac{\partial \mathrm{H}^{2}}{\partial \mathrm{Z}}\right)+ \\
& \frac{\hat{\mu}}{\rho_{\text {hnf }}}\left(\frac{\partial \mathrm{H}_{\mathrm{Z}}}{\partial \mathrm{t}}+\left(\mathrm{H}_{0}+\mathrm{H}_{\mathrm{r}}\right) \frac{\partial \mathrm{H}_{\mathrm{Z}}}{\partial \mathrm{R}}+\mathrm{H}_{\mathrm{Z}} \frac{\partial \mathrm{H}_{\mathrm{Z}}}{\partial \mathrm{Z}}\right)+\frac{(\rho \beta)_{\mathrm{hnf}}}{\rho_{\mathrm{hnf}}} \mathrm{g}\left(\mathrm{T}-\mathrm{T}_{0}\right), \\
& \frac{\partial \mathrm{T}}{\partial \mathrm{t}}+\mathrm{U} \frac{\partial \mathrm{T}}{\partial \mathrm{R}}+\mathrm{W} \frac{\partial \mathrm{T}}{\partial \mathrm{Z}}=\frac{\kappa_{\mathrm{hnf}}}{\left(\rho \mathrm{c}_{\mathrm{p}}\right)_{\mathrm{hnf}}}\left(\frac{\partial^{2} \mathrm{~T}}{\partial \mathrm{R}^{2}}+\frac{1}{\mathrm{R}} \frac{\partial \mathrm{T}}{\partial \mathrm{R}}+\frac{\partial^{2} \mathrm{~T}}{\partial \mathrm{Z}^{2}}\right)+\frac{\mathrm{Q}_{0}}{\left(\rho \mathrm{c}_{\mathrm{p}}\right)_{\mathrm{hnf}}}, \\
& \frac{-1}{\hat{\mu}} \frac{\partial \mathrm{E}}{\partial \mathrm{Z}}=\mathrm{U}\left(-\frac{\partial \mathrm{H}_{\mathrm{r}}}{\partial \mathrm{R}}+\frac{\partial \mathrm{H}_{\mathrm{z}}}{\partial \mathrm{Z}}\right)+\mathrm{H}_{\mathrm{z}} \frac{\partial \mathrm{U}}{\partial \mathrm{Z}}-\left(\mathrm{H}_{0}+\mathrm{H}_{\mathrm{r}}\right) \frac{\partial \mathrm{W}}{\partial \mathrm{Z}}-2 \mathrm{~W} \frac{\partial \mathrm{H}_{\mathrm{r}}}{\partial \mathrm{Z}}+ \\
& \frac{1}{\sigma \hat{\mu}}\left(\frac{\partial^{2} \mathrm{H}_{\mathrm{r}}}{\partial \mathrm{R}^{2}}+\frac{1}{\mathrm{R}} \frac{\partial \mathrm{H}_{\mathrm{r}}}{\partial \mathrm{R}}+\frac{\partial^{2} \mathrm{H}_{\mathrm{r}}}{\partial \mathrm{Z}^{2}}\right), \\
& \frac{-1}{\hat{\mu}} \frac{\partial \mathrm{E}}{\partial \mathrm{R}}=\left(\mathrm{H}_{0}+\mathrm{H}_{\mathrm{r}}\right) \frac{\partial \mathrm{W}}{\partial \mathrm{R}}+\mathrm{W}\left(\frac{\partial \mathrm{H}_{\mathrm{r}}}{\partial \mathrm{R}}-\frac{\partial \mathrm{H}_{\mathrm{z}}}{\partial \mathrm{Z}}\right)-2 \mathrm{U} \frac{\partial \mathrm{H}_{\mathrm{z}}}{\partial \mathrm{R}}-\mathrm{H}_{\mathrm{z}} \frac{\partial \mathrm{U}}{\partial \mathrm{R}}+ \\
& \frac{1}{\sigma \hat{\mu}}\left(\frac{\partial^{2} \mathrm{H}_{\mathrm{z}}}{\partial \mathrm{R}^{2}}+\frac{1}{\mathrm{R}} \frac{\partial \mathrm{H}_{\mathrm{z}}}{\partial \mathrm{R}}+\frac{\partial^{2} \mathrm{H}_{\mathrm{z}}}{\partial \mathrm{Z}^{2}}\right) \text {. }
\end{aligned}
$$

where,

$$
\Phi=\sqrt{\left|2\left[\left(\frac{\partial U}{\partial R}\right)^{2}+\left(\frac{U}{R}\right)^{2}+\left(\frac{\partial W}{\partial Z}\right)^{2}\right]+\left(\frac{\partial U}{\partial Z}+\frac{\partial W}{\partial R}\right)^{2}\right|^{n-1}}
$$

Wave shapes in the laboratory frame for envelope of cilia tips according to Figure 1 can be expressed as:

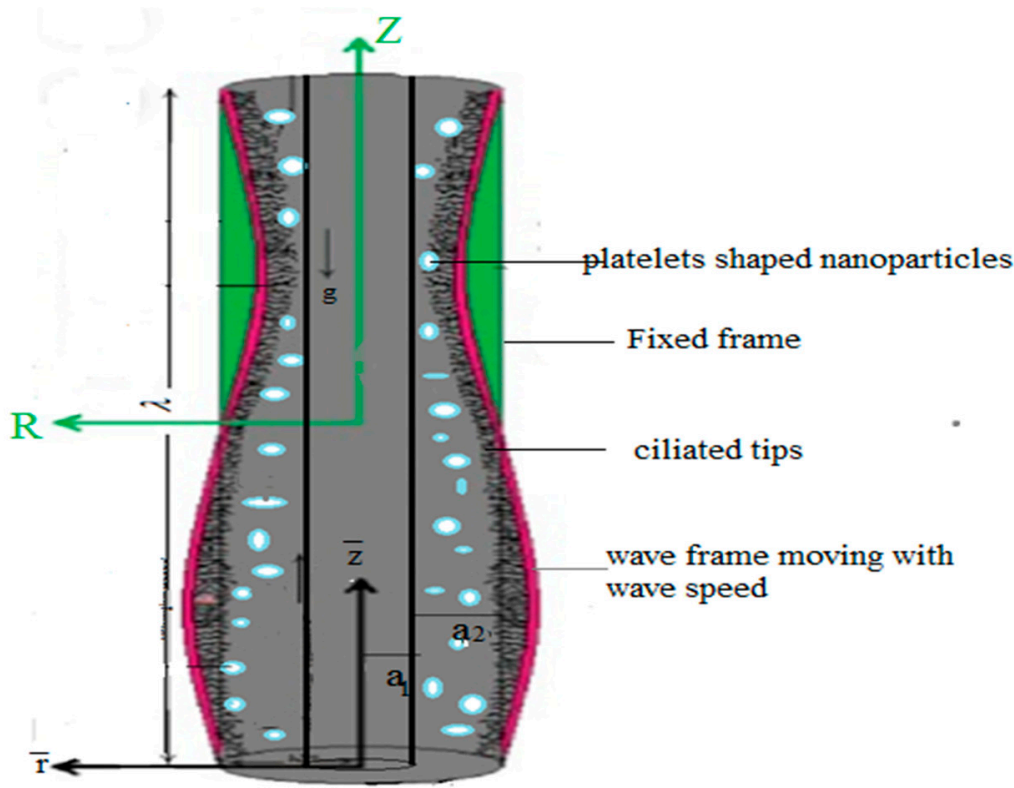

Figure 1. Geometry of the physical problem. 


$$
\begin{gathered}
R_{1}=a_{1}, \\
R_{2}=f(Z, t)=\left[a_{2}+b \cos \left(\frac{2 \pi}{\lambda}(Z-c t)\right)\right]
\end{gathered}
$$

where, $\alpha_{1}$ and $\alpha_{2}$ represents radii of internal and external cylindrical tubes, accordingly. Considering the motion of cilia in an elliptical path, the vertical position of cilia tips is expressed as:

$$
Z=g\left(Z, Z_{0}, t\right)=\left[Z_{0}+\alpha b \operatorname{Sin}\left(\frac{2 \pi}{\lambda}(Z-c t)\right)\right]
$$

Since the velocities of the fluid layers are similar to those of the cilia tips under the no-slip wall conditions, the vertical and horizontal velocities are:

$$
\begin{aligned}
& \mathrm{W}=\left.\frac{\partial \mathrm{Z}}{\partial \mathrm{t}}\right|_{\mathrm{Z}_{0}}=\frac{\partial g}{\partial \mathrm{t}}+\frac{\partial g}{\partial \mathrm{Z}} \frac{\partial \mathrm{Z}}{\partial \mathrm{t}}, \\
& \mathrm{U}=\left.\frac{\partial \mathrm{R}}{\partial \mathrm{t}}\right|_{\mathrm{Z}_{0}}=\frac{\partial f}{\partial \mathrm{t}}+\frac{\partial f}{\partial \mathrm{Z}} \frac{\partial \mathrm{Z}}{\partial \mathrm{t}} .
\end{aligned}
$$

With the help of Equations (10) and (11), Equation (12) becomes:

$$
\text { At } R=R_{2} W=\frac{\frac{-2 \pi}{\lambda} b \alpha c \operatorname{Cos}\left(\frac{2 \pi}{\lambda}(Z-c t)\right)}{1-\frac{2 \pi}{\lambda} b \alpha c \operatorname{Cos}\left(\frac{2 \pi}{\lambda}(Z-c t)\right)}, U=\frac{\frac{2 \pi}{\lambda} b \alpha c \operatorname{Sin}\left(\frac{2 \pi}{\lambda}(Z-c t)\right)}{1-\frac{2 \pi}{\lambda} b \alpha c \operatorname{Cos}\left(\frac{2 \pi}{\lambda}(Z-c t)\right)}
$$

The associated boundary conditions are defined as:

$$
\mathrm{W}=0, \text { at } \mathrm{R}=\mathrm{R}_{1}, \mathrm{~W}=\frac{\frac{-2 \pi}{\lambda} \mathrm{b} \alpha \mathrm{c} \operatorname{Cos}\left(\frac{2 \pi}{\lambda}(\mathrm{Z}-\mathrm{ct})\right)}{1-\frac{2 \pi}{\lambda} \mathrm{b} \alpha \mathrm{C} \operatorname{Cos}\left(\frac{2 \pi}{\lambda}(\mathrm{Z}-\mathrm{ct})\right)} \text { at } \mathrm{R}=\mathrm{R}_{1}
$$

If $(\mathrm{R}, \mathrm{Z}, \mathrm{U}, \mathrm{W})$ and $(\mathrm{r}, \mathrm{z}, \mathrm{u}, \mathrm{w})$ are, respectively, the coordinates and velocities in the laboratory and wave frame, then transformations from the laboratory frame to wave frame for a steady problem are [48]:

$$
\begin{gathered}
\mathrm{r}=\mathrm{R}, \mathrm{z}=\mathrm{Z}-\mathrm{ct}, \mathrm{p}(\mathrm{r}, \mathrm{z})=\mathrm{P}(\mathrm{R}, \mathrm{Z}-\mathrm{ct}), \mathrm{u}(\mathrm{r}, \mathrm{z})=\mathrm{U}(\mathrm{R}, \mathrm{Z}-\mathrm{ct}), \\
\mathrm{w}(\mathrm{r}, \mathrm{z})=\mathrm{W}(\mathrm{R}, \mathrm{Z}-\mathrm{ct})-\mathrm{c} .
\end{gathered}
$$

We introduce the following dimensionless quantities in the wave frame as [29,31]:

$$
\begin{aligned}
& \overline{\mathrm{r}}=\frac{\mathrm{r}}{\mathrm{a}_{2}}, \overline{\mathrm{z}}=\frac{\mathrm{z}}{\lambda}, \delta=\frac{\mathrm{a}_{2}}{\lambda}, \overline{\mathrm{r}}_{1}=\frac{\mathrm{r}_{1}}{\mathrm{a}_{2}}=\xi, \overline{\mathrm{r}}_{2}=\frac{\mathrm{r}_{2}}{\mathrm{a}_{\mathrm{a}^{2}}}, \overline{\mathrm{u}}=\frac{\lambda \mathrm{u}}{\mathrm{a}_{2} \mathrm{c}}, \overline{\mathrm{w}}=\frac{\mathrm{w}}{\mathrm{c}}, \overline{\mathrm{t}}=\frac{\mathrm{ct}}{\lambda}, \\
& \bar{\phi}=\frac{\phi}{\mathrm{H}_{0} \mathrm{a}_{2}}, \bar{\psi}=\frac{\psi}{\mathrm{a}_{2} \mathrm{c}}, \overline{\mathrm{H}}_{\mathrm{r}}=-\frac{\delta}{\overline{\mathrm{r}}} \frac{\partial \bar{\phi}}{\partial \overline{\mathrm{z}}}, \overline{\mathrm{H}}_{\mathrm{z}}=\frac{1}{\overline{\mathrm{r}}} \frac{\partial \bar{\phi}}{\partial \overline{\mathrm{r}}}, \overline{\mathrm{u}}=-\frac{\delta}{\overline{\mathrm{r}}} \frac{\overline{\overline{\mathrm{z}}}}{\partial \mathrm{z}}, \varepsilon=\frac{\mathrm{b}}{\mathrm{a}_{2}}, \\
& \overline{\mathrm{w}}=\frac{1}{\overline{\mathrm{r}}} \frac{\partial \bar{\psi}}{\partial \overline{\mathrm{r}}}, \overline{\mathrm{p}}=\frac{\mathrm{a}_{2}{ }^{\mathrm{n}+1} \mathrm{p}}{\mathrm{c}^{\mathrm{n}} \lambda \mathrm{k}}, \theta=\frac{\mathrm{T}-\mathrm{T}_{1}}{\mathrm{~T}_{0}-\mathrm{T}_{1}}, \overline{\mathrm{E}}=-\frac{\mathrm{E}}{\mathrm{cH}_{0} \hat{\mu}} .
\end{aligned}
$$

A non-dimensional governing model for the aforementioned quantities along with long wavelength and creeping Stokesian flow approach is:

$$
\begin{aligned}
& \frac{\partial \mathrm{p}}{\partial \mathrm{z}}+\frac{1}{\mathrm{r}}\left(-\frac{1}{\mathrm{r}^{2}} \frac{\partial \psi}{\partial \mathrm{r}}+\frac{1}{\mathrm{r}} \frac{\partial^{2} \psi}{\partial \mathrm{r}^{2}}\right)^{2}+2\left(-\frac{1}{\mathrm{r}^{2}} \frac{\partial \psi}{\partial \mathrm{r}}+\frac{1}{\mathrm{r}} \frac{\partial^{2} \psi}{\partial \mathrm{r}^{2}}\right)\left(\frac{2}{\mathrm{r}^{3}} \frac{\partial \psi}{\partial \mathrm{r}}-\frac{2}{\mathrm{r}^{2}} \frac{\partial^{2} \psi}{\partial \mathrm{r}^{2}}+\frac{1}{\mathrm{r}} \frac{\partial^{3} \psi}{\partial \mathrm{r}^{3}}\right)- \\
& \mathrm{M}^{2}\left(\mathrm{E}-\frac{1}{\mathrm{r}} \frac{\partial \psi}{\partial \mathrm{r}}\right)-\mathrm{A}_{1} \mathrm{Gr} \theta=0
\end{aligned}
$$


Equation (17) is simplified in the form:

$$
\begin{gathered}
-\frac{1}{r^{2}}\left(-\frac{1}{r^{2}} \frac{d \psi}{d r}+\frac{1}{r} \frac{d^{2} \psi}{d r^{2}}\right)^{2}+\frac{2}{r}\left(-\frac{1}{r^{2}} \frac{d \psi}{d r}+\frac{1}{r} \frac{d^{2} \psi}{d r^{2}}\right)\left(\frac{2}{r^{3}} \frac{d \psi}{d r}-\frac{2}{r^{2}} \frac{d^{2} \psi}{d r^{2}}+\frac{1}{r} \frac{d^{3} \psi}{d r^{3}}\right) \\
+2\left(-\frac{1}{r^{2}} \frac{d \psi}{d r}+\frac{1}{r} \frac{d^{2} \psi}{d r^{2}}\right)\left(-\frac{6}{r^{4}} \frac{d \psi}{d r}+\frac{6}{r^{3}} \frac{d^{2} \psi}{d r^{2}}-\frac{3}{r^{2}} \frac{d^{3} \psi}{d r^{3}}+\frac{1}{r} \frac{d^{4} \psi}{d r^{4}}\right) \\
+2\left(\frac{2}{r^{3}} \frac{d \psi}{d r}-\frac{2}{r^{2}} \frac{d^{2} \psi}{d r^{2}}+\frac{1}{r} \frac{d^{3} \psi}{d r^{3}}\right)^{2}+M^{2}\left(-\frac{1}{r^{2}} \frac{d \psi}{d r}+\frac{1}{r} \frac{d^{2} \psi}{d r^{2}}\right)-A_{1} G r \frac{d \theta}{d r}=0, \\
\frac{1}{\mathrm{r}} \frac{\partial \theta}{\partial \mathrm{r}}+\frac{\partial^{2} \theta}{\partial \mathrm{r}^{2}}+\frac{\Omega}{\mathrm{A}_{2}}=0, \\
\mathrm{E}-\frac{1}{\mathrm{r}} \frac{\partial \psi}{\partial \mathrm{r}}-\frac{1}{\mathrm{R}_{\mathrm{m}}}\left(-\frac{1}{\mathrm{r}^{2}} \frac{\partial \phi}{\partial \mathrm{r}}+\frac{1}{\mathrm{r}} \frac{\partial^{2} \phi}{\partial \mathrm{r}^{2}}\right)=0 .
\end{gathered}
$$

where, bar notation is ignored.

Corresponding boundary conditions are listed as:

$$
\begin{aligned}
& \psi(\mathrm{r})=-\frac{\mathrm{F}}{2}, \frac{1}{\mathrm{r}} \frac{\partial \psi}{\partial \mathrm{r}}=-1, \phi(\mathrm{r})=0, \theta(\mathrm{r})=1, \text { at } \mathrm{r}=\mathrm{r}_{1}=\xi, \\
& \psi(\mathrm{r})=\frac{\mathrm{F}}{2}, \frac{1}{\mathrm{r}} \frac{\partial \psi}{\partial \mathrm{r}}=-1-2 \pi \varepsilon \alpha \delta \cos (2 \pi \mathrm{z}), \phi(\mathrm{r})=1, \\
& \theta(\mathrm{r})=0, \text { at } \mathrm{r}=\mathrm{r}_{2}=1+\varepsilon \cos (2 \pi \mathrm{z}) .
\end{aligned}
$$

In the above expressions, $u$ and $w$ denotes $r$-and $z$-components of velocity within the wave frame, respectively. Emerging parameters in the above model are expressed as $[48,49]$ :

$$
\begin{aligned}
& \mathrm{M}^{2}=\operatorname{ReS}^{2} \mathrm{R}_{\mathrm{m}}, \operatorname{Re}=\frac{\mathrm{a}_{2}^{\mathrm{n}} \rho_{\mathrm{f}}}{\mathrm{kc}^{\mathrm{n}-2}}, \mathrm{R}_{\mathrm{m}}=\sigma \hat{\mu} \mathrm{a}_{2} \mathrm{c}, \mathrm{S}=\frac{\mathrm{H}_{0}}{\mathrm{c}} \sqrt{\frac{\hat{\mu}}{\rho_{\mathrm{f}}}} \\
& \mathrm{p}_{\mathrm{m}}=\mathrm{p}+\frac{1}{2} \operatorname{Re} \delta \frac{\hat{\mu}(\mathrm{H})^{2}}{\mathrm{c}^{2} \rho_{\mathrm{f}}}, \Omega=\frac{\mathrm{Q}_{0} \mathrm{a}_{2}^{2}}{\mathrm{k}_{\mathrm{f}}\left(\mathrm{T}_{0}-\mathrm{T}_{1}\right)}, \mathrm{Gr}=\frac{(\rho \beta)_{\mathrm{f}}\left(\mathrm{T}_{0}-\mathrm{T}_{1}\right) \mathrm{a}_{2}^{\mathrm{n}+1}}{\mathrm{kc}^{\mathrm{n}}} .
\end{aligned}
$$

where as

$$
\begin{aligned}
& \left.\mathrm{A}_{1}=\left(1-\phi_{1}-\phi_{2}\right)+\phi_{1}\left(\frac{(\rho \beta)_{s_{1}}}{(\rho \beta)_{\mathrm{f}}}\right)\right]+\phi_{2} \frac{(\rho \beta)_{s_{2}}}{(\rho \beta)_{\mathrm{f}}}, \\
& \mathrm{A}_{2}=\frac{\kappa_{\mathrm{s}_{2}}+(\mathrm{s}-1) \kappa_{\mathrm{bf}}-(\mathrm{s}-1) \phi_{2}\left(\kappa_{\mathrm{b}}-\kappa_{\mathrm{s}_{2}}\right)}{\kappa_{\mathrm{s}_{2}}+(\mathrm{s}-1) \kappa_{\mathrm{bf}}+\phi_{2}\left(\kappa_{\mathrm{bf}}-\kappa_{\mathrm{s}_{2}}\right)} \frac{\kappa_{\mathrm{s}_{1}}+(\mathrm{s}-1) \kappa_{\mathrm{f}}-(\mathrm{s}-1) \phi_{1}\left(\kappa_{\mathrm{f}}-\kappa_{\mathrm{s}_{1}}\right)}{\kappa_{\mathrm{s}_{1}}+(\mathrm{s}-1) \kappa_{\mathrm{f}}+\phi_{1}\left(\kappa_{\mathrm{f}}-\kappa_{\mathrm{s}_{1}}\right)} .
\end{aligned}
$$

Moreover, the pressure gradient can be achieved from the following relation:

$$
F=\int_{r_{1}}^{r_{2}} r w d r=\int_{r_{1}}^{r_{2}} \frac{\partial \psi}{\partial r} d r
$$

where, $F$ is the volumetric rate of flow inside the wave frame. Now, non-dimensional mean flow rate $Q$ into the laboratory frame assuming the transformations of Equations (16) is:

$$
Q=F+\frac{1}{2}\left(1-\xi^{2}+\frac{\varepsilon^{2}}{2}\right) .
$$

Pressure rise per wavelength is calculated utilizing Equation (25) as:

$$
\Delta P=\int_{0}^{1} \frac{d p}{d z} d z .
$$

All variables and parameter are defined in Appendix A. 


\section{Methodology and Convergence of HAM Solutions}

\subsection{Methodology}

The dimensionless governing model containing Equations (19)-(21) under the associated boundary conditions (22) is analyzed by employing homotopy analysis method. For this, the initial guesses are $\psi_{0}(r), \phi_{0}(r)$ and $\theta_{0}(r)$ and linear operators are chosen in the subsequent manner as:

$$
L_{1}(\psi)=\psi^{(i v)}, L_{2}(\phi)=\phi^{\prime \prime}, L_{3}(\theta)=\theta^{\prime \prime} .
$$

And

$$
L_{1}\left(C_{1}+C_{2} r+C_{3} r^{2}+C_{4} r^{3}\right)=L_{2}\left(C_{5}+C_{6} r\right)=L_{3}\left(C_{7}+C_{8} r\right)=0
$$

where, $C_{1}-C_{8}$ represents constants while $h_{1}, h_{2}$ and $h_{3}$ being auxiliary parameter which plays a key role in the frame of HAM, since the convergence of solutions strongly depends on $h$. Now, for embedding parameter $\gamma \in[0,1]$ and non-zero auxiliary parameters, the problem under study can be constructed in the following manner [29,30]:

Zeroth-order deformation problem:

$$
\begin{aligned}
& (1-\gamma) L_{1}\left[\psi(r, \gamma)-\psi_{0}(r)\right]=\gamma h_{1} N_{1}[\psi(r, \gamma), \phi(r, \gamma), \theta(r, \gamma)], \\
& (1-\gamma) L_{2}\left[\phi(r, \gamma)-\phi_{0}(r)\right]=\gamma h_{2} N_{2}[\psi(r, \gamma), \phi(r, \gamma), \theta(r, \gamma)], \\
& (1-\gamma) L_{3}\left[\theta(r, \gamma)-\theta_{0}(r)\right]=\gamma h_{3} N_{3}[\psi(r, \gamma), \phi(r, \gamma), \theta(r, \gamma)] .
\end{aligned}
$$

and,

$$
\begin{aligned}
& \text { At } r=r_{1}=\xi, \psi\left(r_{1}, \gamma\right)=-\frac{F}{2}, \frac{1}{r_{1}} \psi^{\prime}\left(r_{1}, \gamma\right)=-1, \phi\left(r_{1}, \gamma\right)=0, \theta\left(r_{1}, \gamma\right)=1 . \\
& \text { At } r=r_{2}=1+\varepsilon \cos (2 \pi z), \psi\left(r_{2}, \gamma\right)=\frac{F}{2}, \frac{1}{r_{2}} \psi^{\prime}\left(r_{2}, \gamma\right)=-1-2 \pi \varepsilon \alpha \delta \cos (2 \pi z), \\
& \phi\left(r_{2}, \gamma\right)=1, \theta\left(r_{2}, \gamma\right)=0 .
\end{aligned}
$$

On the basis of selected linear operator, auxiliary parameter and initial guesses, the $\mathrm{m}$ th order solution series is constructed as:

$$
\begin{aligned}
& L_{1}\left[\psi_{m}(r, \gamma)-\chi_{m} \psi_{m-1}(r, \gamma)\right]=h_{1} R_{m}^{1}(r, \gamma), \\
& L_{2}\left[\phi_{m}(r, \gamma)-\chi_{m} \phi_{m-1}(r, \gamma)\right]=h_{2} R_{m}^{2}(r, \gamma), \\
& L_{3}\left[\theta_{m}(r, \gamma)-\chi_{m} \theta_{m-1}(r, \gamma)\right]=h_{3} R_{m}^{3}(r, \gamma) .
\end{aligned}
$$

The boundary conditions are:

$$
\begin{gathered}
\text { at } r=r_{1}=\xi, \psi_{m}\left(r_{1}, \gamma\right)=0, \frac{1}{r_{1}} \psi_{m}^{\prime}\left(r_{1}, \gamma\right)=0, \phi_{m}\left(r_{1}, \gamma\right)=0, \theta_{m}\left(r_{1}, \gamma\right)=0 . \\
\text { at } r=r_{2}=1+\varepsilon \cos (2 \pi z), \psi_{m}\left(r_{2}, \gamma\right)=0, \frac{1}{r_{2}} \psi_{m}^{\prime}\left(r_{2}, \gamma\right)=0, \phi_{m}\left(r_{2}, \gamma\right)=0, \\
\theta_{m}\left(r_{2}, \gamma\right)=0 .
\end{gathered}
$$

where the auxiliary parameter is found by plotting $h$-curves while $\chi_{m}$ is defined as:

$$
\left.\chi_{m}=\begin{array}{ll}
0, & \mathrm{~m} \leq 1 \\
1, & \mathrm{~m}>1
\end{array}\right\}
$$

Therefore, we can write:

$$
\begin{gathered}
\psi_{m}(r, \gamma)=\Psi_{m}(r, \gamma)+C_{1}+C_{2} r+C_{3} r^{2}+C_{4} r^{3}, \\
\phi_{m}(r, \gamma)=\Phi_{m}(r, \gamma)+C_{5}+C_{6} r \\
\theta_{m}(r, \gamma)=\Theta_{m}(r, \gamma)+C_{7}+C_{8} r .
\end{gathered}
$$


The particular solutions $\Psi_{m}(r, \gamma), \Phi_{m}(r, \gamma)$ and $\Theta_{m}(r, \gamma)$ are obtained using a symbolic software mathematica while the constants are determined from the defined boundary conditions.

\subsection{Convergence of HAM Solutions}

To obtain the values of auxiliary parameters $h_{1}, h_{2}$ and $h_{3}$, h-curves against $\psi^{\prime \prime}, \phi^{\prime \prime}$ and $\theta^{\prime}$ are prepared and the results are given in Figures 2-4. Convergence intervals lie in the flat portion of these $h$-curves as witnessed from plots. It is observed those permissible values of $h_{1}, h_{2}$ and $h_{3}$ up to the 10th order of approximation are: $-0.1 \leq \mathrm{h}_{1} \leq 0.3,-0.12 \leq \mathrm{h}_{2} \leq 0.01,-0.2 \leq \mathrm{h}_{3} \leq 0.05$.

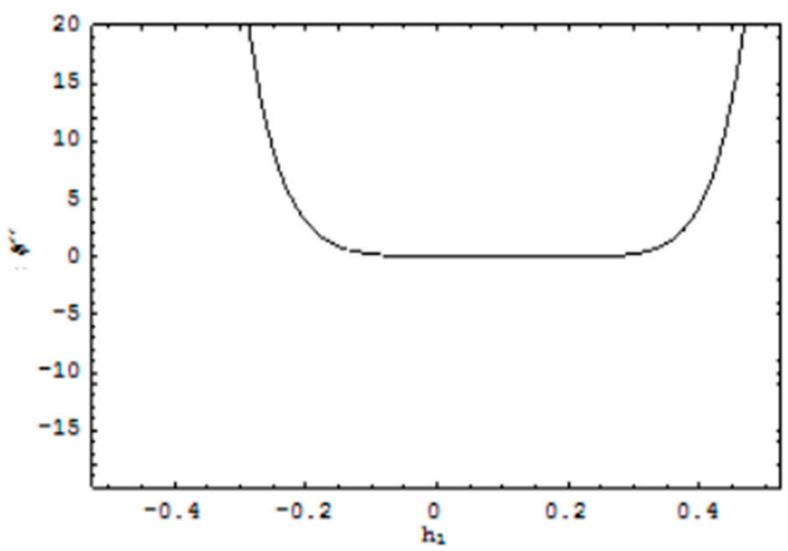

Figure 2. $h$-curve for the $\psi$ at $z=1, Q=2, \varepsilon=0.2$.

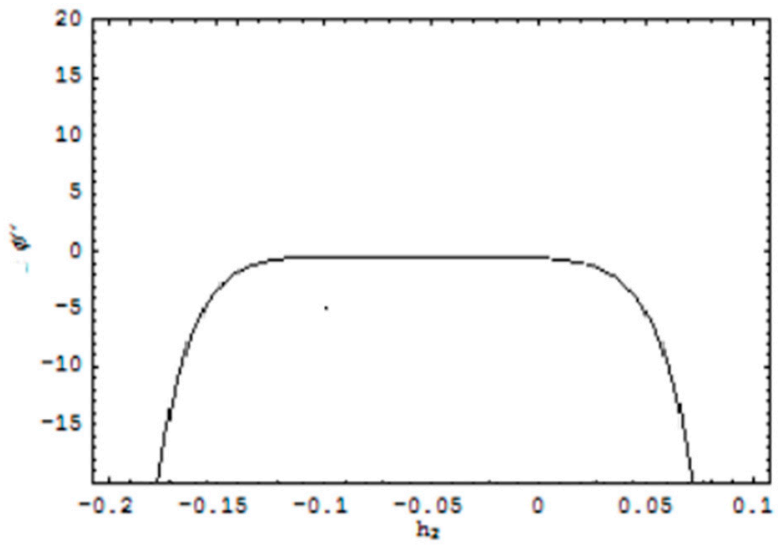

Figure 3. $h$-curve for the $\phi$ at $\mathrm{z}=1, \mathrm{Q}=2, \varepsilon=0.2$.

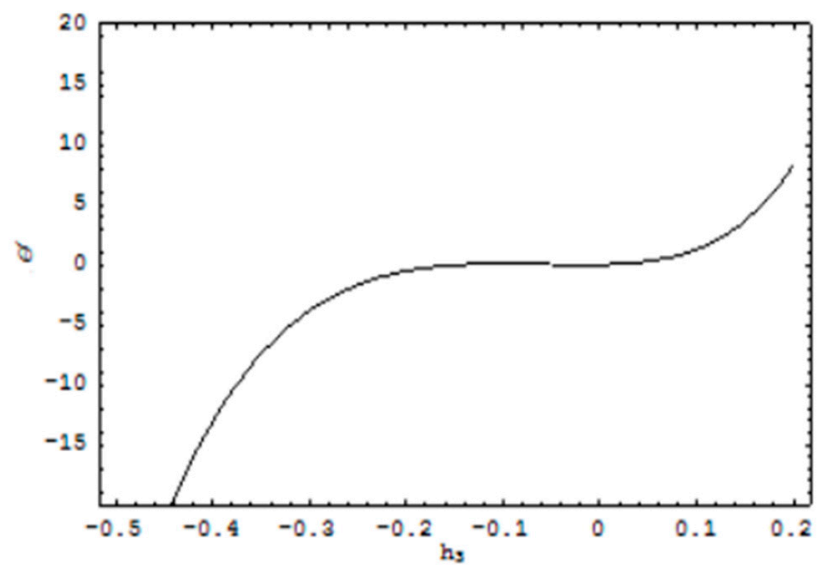

Figure 4. $h$-curve for the $\theta$ at $z=1, Q=2, \varepsilon=0.2$. 


\section{Quantitative Analysis}

The governing model is tackled analytically and solutions are physically interpreted here.

The problem of rheological behavior of hybrid nanofluid flow induced by metachronical ciliary transport with heat transfer is studied. Important physical features of water and nanomaterials are represented in Table 1. Therefore, the behavior of velocity, temperature, induced magnetic field, stream function and volumetric flow rate for involving parameters is discussed in this section. Magnitudes of physical parameters are chosen corresponding to the physical situations assumed in the problem with $\mathrm{z}=1, \varepsilon=0.2, \alpha=0.05$ and $\delta=0.002$.

Figure 5 explores the variational trend of axial velocity for escalating values of magnetic Reynolds number. As the magnetic Reynolds number rises, a high induction effects appear with the reduction in magnetic diffusion. These effects can be observed from the figure in which the velocity inside the annulus shows a decreasing behavior in the vicinity of the inner tube having radius $a_{1}$ owing to no slip velocity condition while it accelerates near the interior of outer tube with radius $a_{2}$ due to the continuous cilia beating. Moreover, a similar trend is noticed in Figures 6 and 7 for rising values of $\mathrm{Gr}$ and $M$ caused by increasing buoyancy effects towards the variation in $G r$ and due to adding the flow mechanism with a rise in $M$ which directly affects the flow rate. Figure 8 explicates the variational trend of magnetic induction profile against $R$. This is due to the fact that induction is directly linked with advection and the effects of $R$ on the flow rate as described in Figure 5, cause magnetic induction profile to decelerate near the boundary of inner tube and accelerate in the vicinity of outer tube.

The consequences of emerging parameters on the temperature profile are inferred in Figures 9 and 10. Correspondingly, a decrease in temperature of the hybrid nanofluid for gradually mounting values of $G r$ is observed in Figure 9. The physics behind such behavior is an increase in heat-transfer rate due to enhancing buoyancy forces for rise in values of $G r$. An increasing response of temperature of the fluid towards the magnetic Reynolds number is noted in Figure 10. This reveals that for high values of $R$, fluid particles gain more kinetic energy which is directly related to fluid temperature. All the results are plotted for mean flow rate $Q=2$.

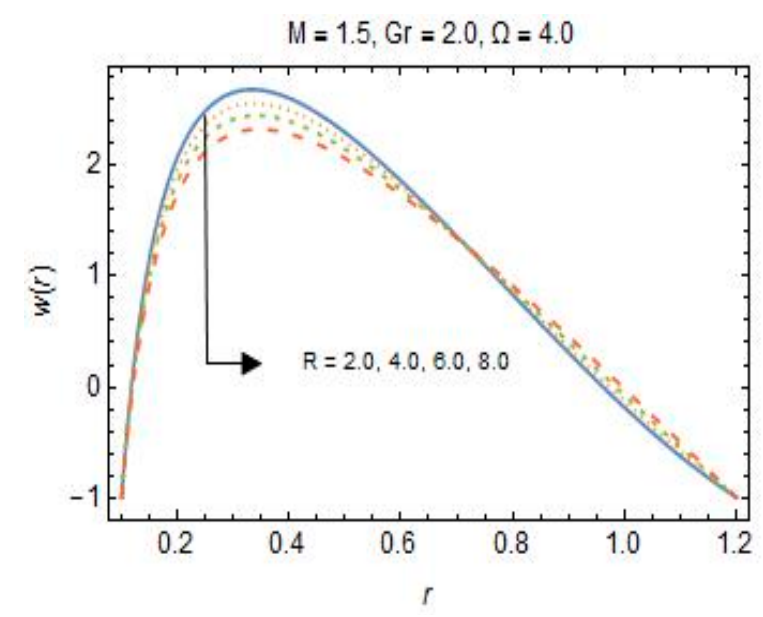

Figure 5. Variation in $w(r)$ towards $R$. 


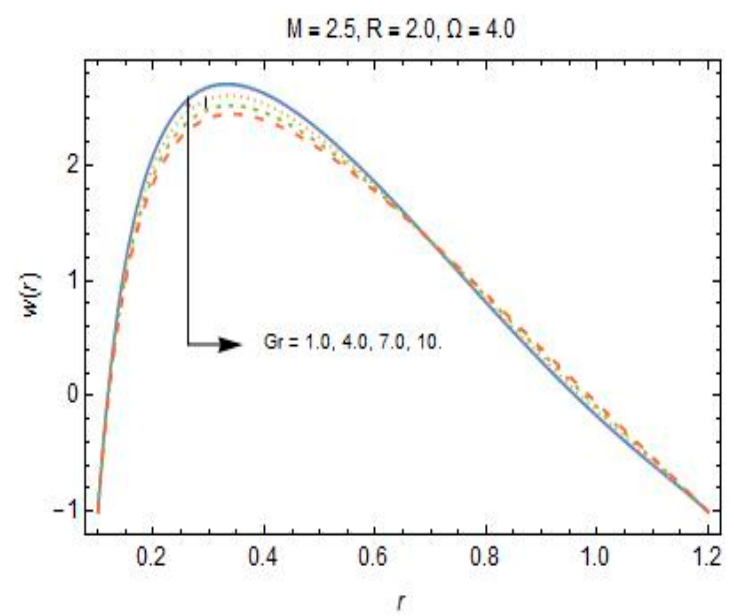

Figure 6. Variation in $w(r)$ towards $G r$.

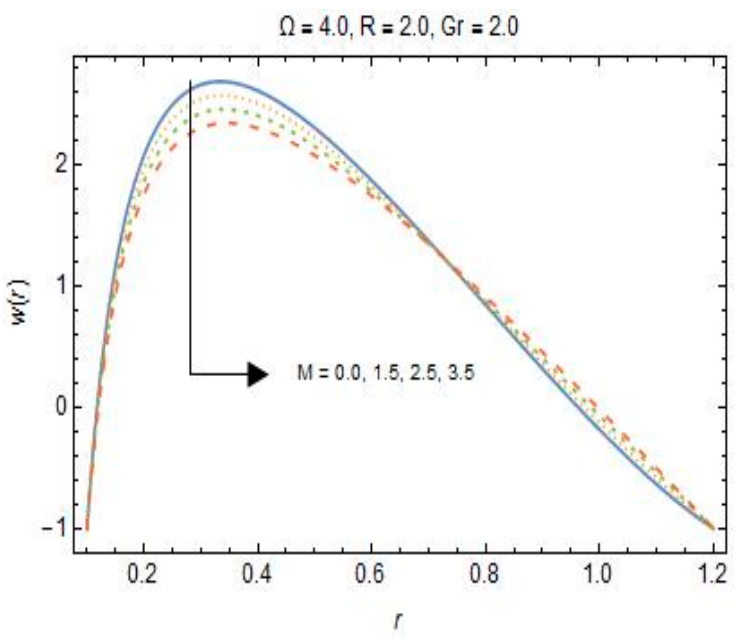

Figure 7. Variation in $w(r)$ towards $M$.

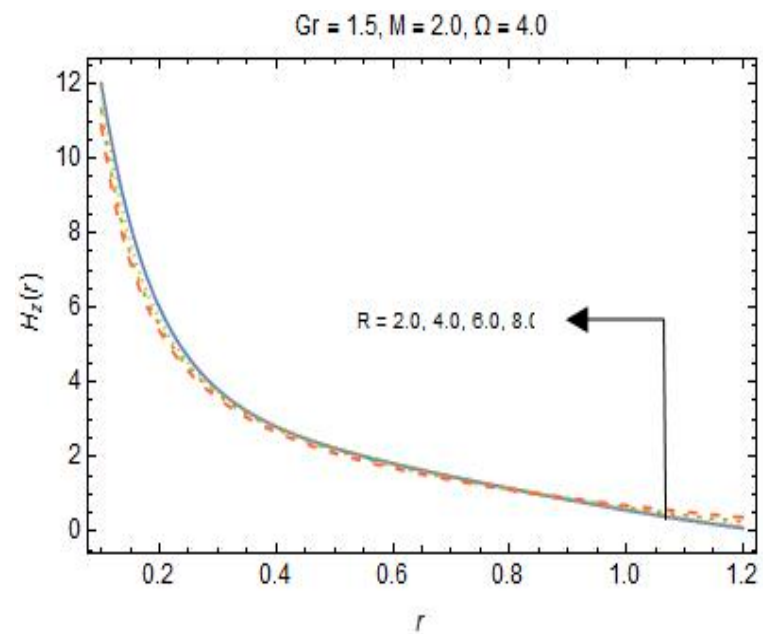

Figure 8. Variation in $H_{z}(r)$ towards $R$. 


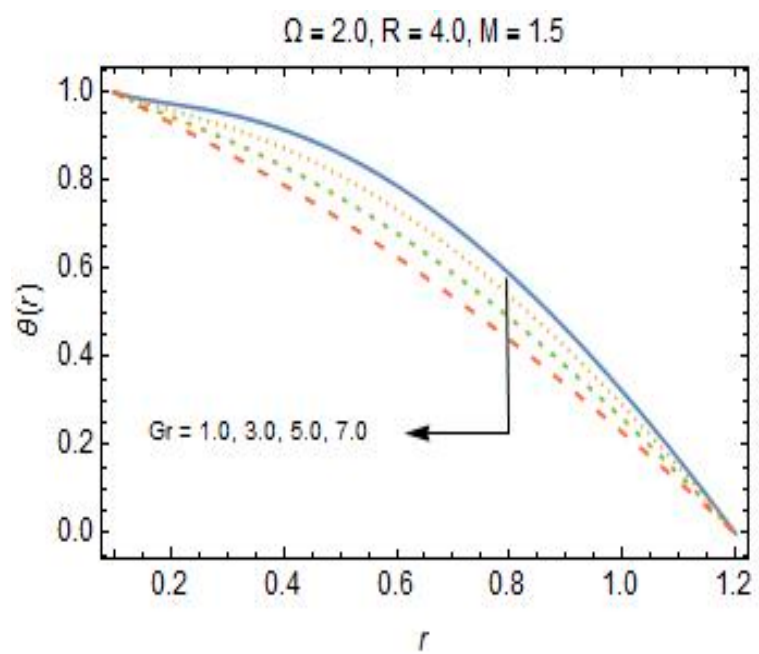

Figure 9. Variation in $\theta(\mathrm{r})$ towards $G_{r}$.

Furthermore, there is a three-dimensional physical interpretation of the velocity profile for variation in values of magnetic Reynolds number, Grashof number and Hartmann number, as displayed in Figures 11-13, respectively. The velocity maps out the parabolic trajectory for all the involving parameters. It is seen that velocity profile changes its behavior in the intervals $0.1 \leq r \leq 0.6$ and 0.61 $\leq \Upsilon \leq 1.0$ and the influences of the parameters on axial velocity are similar to the two dimensional velocity behaviors.

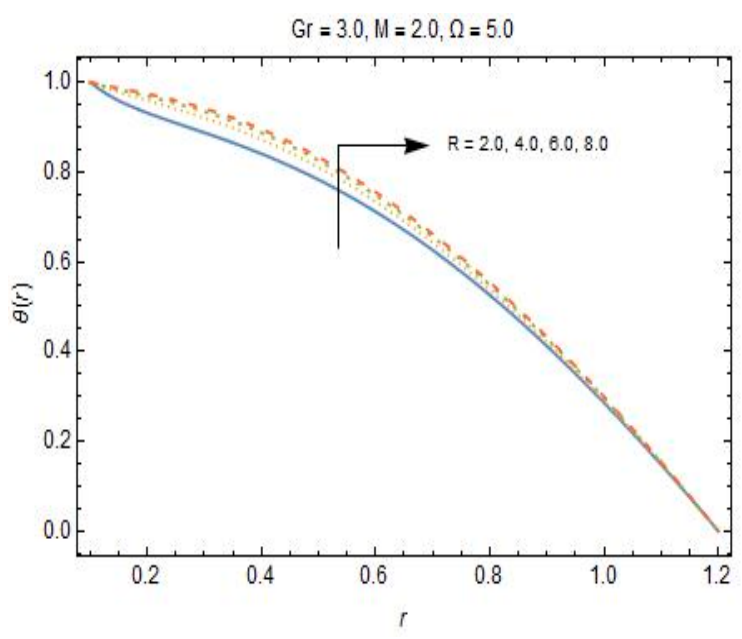

Figure 10. Variation in $\theta(\mathrm{r})$ towards $R$.

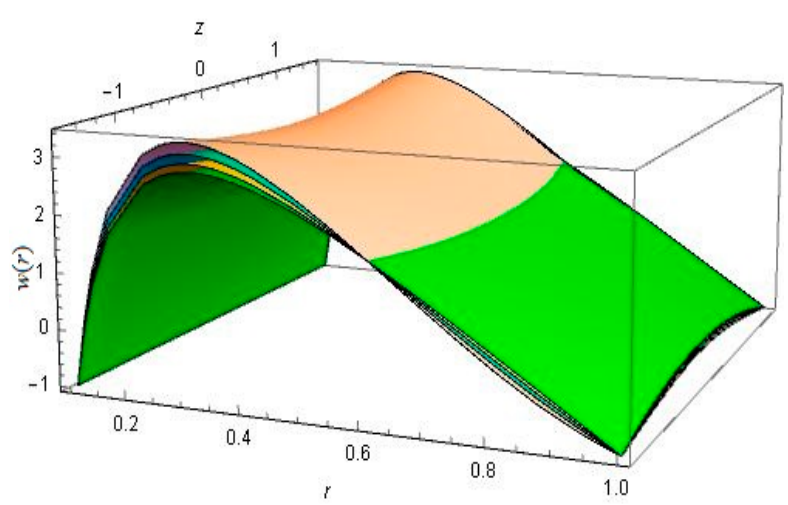

Figure 11. Three-dimensional (3-D) velocity profile towards $R$. 


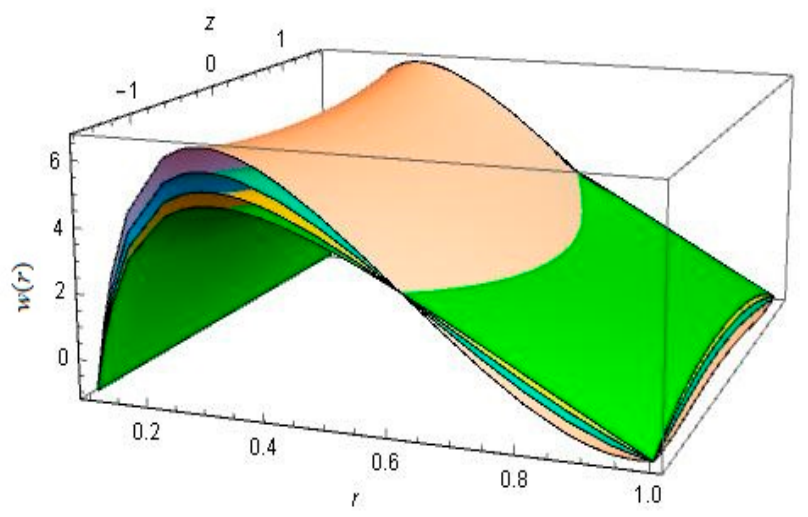

Figure 12. Three-dimensional (3-D) velocity profile towards Gr.

Besides this, the maximum pressure rise towards which peristalsis behaves as a pump is analyzed by means of pressure rise for one wavelength. In this regard, Figures 14-17 are prepared which exhibit the influence of embedding parameters correspond to pressure rise per wavelength towards mean flow rate. Non-linear behavior of these curves characterizes non-Newtonian fluid. All these plots contain four main parts (a) peristaltic pumping region, i.e., $\Delta P>0,(b)$ free pumping region, i.e., $\Delta P=0(c)$ co-pumping region, i.e., $\Delta P<0$. In the region of peristaltic pumping, flow rate is positive and caused by peristalsis that occurred due to overcoming pressure difference while peristalsis of the boundaries of tube yields a free-pumping region. In the region of co-pumping, flow due to the peristalsis is assisted by negative pressure difference. The influence of the heat-generation parameter and Hartmann number are shown in Figures 14 and 15, and it is perceived that the pressure rise in co-pumping region $(-1.0 \leq Q \leq-0.45)$ for $G r$ and $(-1.0 \leq Q \leq 0.5)$ for $M$ are decreasing. As, for $\Omega=0.1,0.3,0.5,0.7$ and $\mathrm{M}=0.0,0.5,1.0,1.5$, corresponding co-pumping regions contain $(Q \in[-1.0,-0.45], Q \in[-1.0,-0.42]$, $Q \in[-1.0,-0.4], Q \in[-1.0,-0.39])$ and $(Q \in[-1.0,0.5], Q \in[-1.0,0.48], Q \in[-1.0,-0.56], Q \in[-1.0$, $-0.4]$ ), respectively. Pumping and free-pumping regions are increasing due to temperature gradient by buoyancy effects and increasing induction, correspondingly. Moreover, a similar trend for a rise in the values of $G r$ and $R$ is depicted in Figures 16 and 17, and it is witnessed that the co-pumping region contains $Q \in[-1.0,-0.4]$ but the pumping region is increasing.

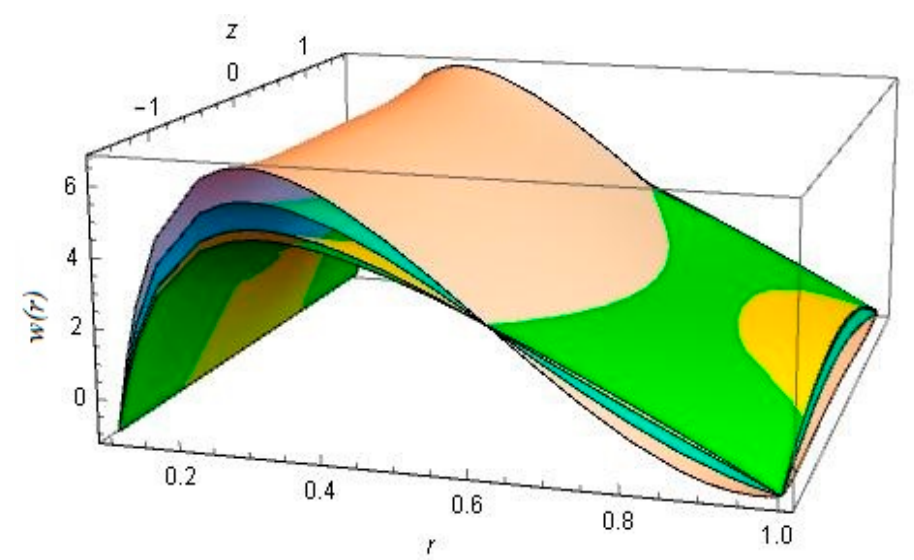

Figure 13. Three-dimensional (3-D) velocity profile towards $M$. 
$\longrightarrow \Omega=0.1 \quad-\cdot \Omega=0.3$

.......... $\Omega=0.5 \quad \ldots \ldots . . \Omega=0.7$

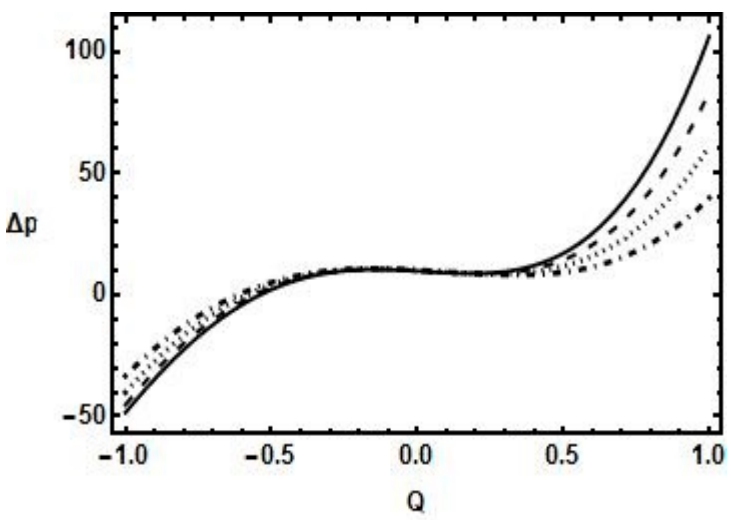

Figure 14. Pressure rise versus $Q$ for $\Omega$.

The pressure gradient illustrates a direction and rate of rapid variation in pressure. Therefore, the pressure gradient towards embedding parameters such as the heat-generation parameter $(\Omega)$, Hartmann number $(M)$, magnetic Reynolds number $(R)$ and Grashof number $(G r)$ are studied and portrayed in Figures 18-21. It is perceived from these plots that the pressure gradient decreases rapidly with the variation in all the parameters. Hence, flow can easily pass through the endoscope for a small pressure gradient at $r=1$ (near outer tube) exclusive of the imposition of the high-pressure gradient.

$\longrightarrow M=0.0 \quad \cdots M=0.5$

.......... $M=1.0 \quad$..... $M=1.5$

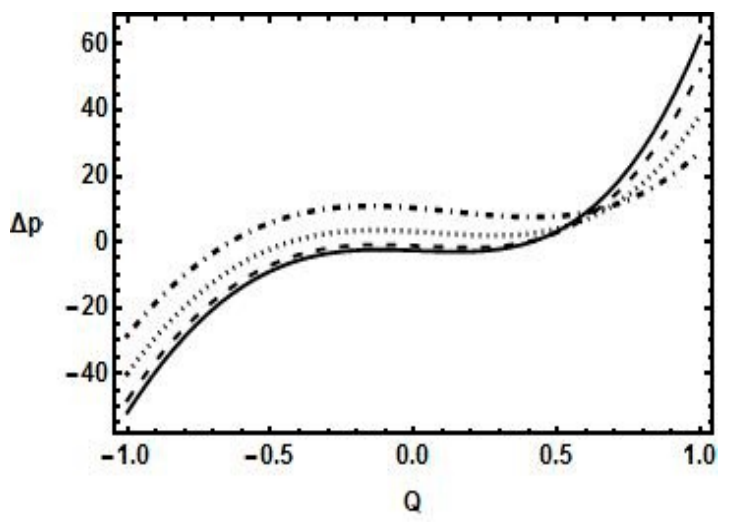

Figure 15. Pressure rise versus $Q$ for $M$. 
$\longrightarrow \mathrm{Gr}=0.6 \quad \cdots \mathrm{Gr}=1.2$

."m!n' $\mathrm{Gr}=1.8 \quad \cdots \cdots \mathrm{Gr}=2.4$

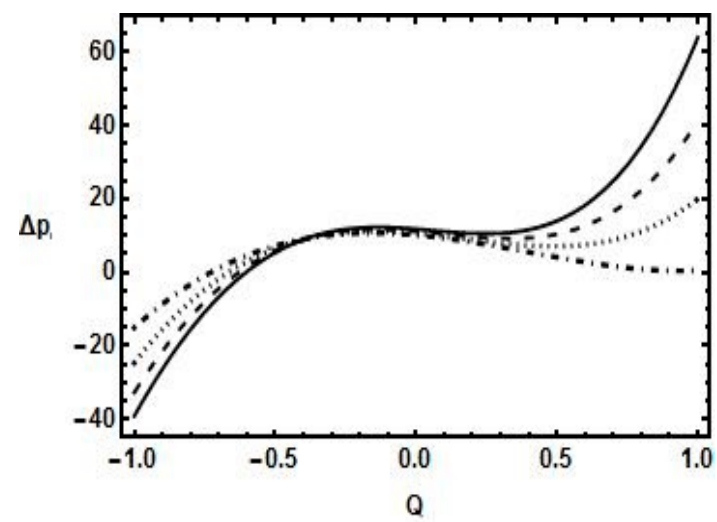

Figure 16. Pressure rise versus $Q$ for $G r$.

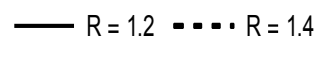$$
\text { .......... } R=1.6 \text {...... } R=1.8
$$

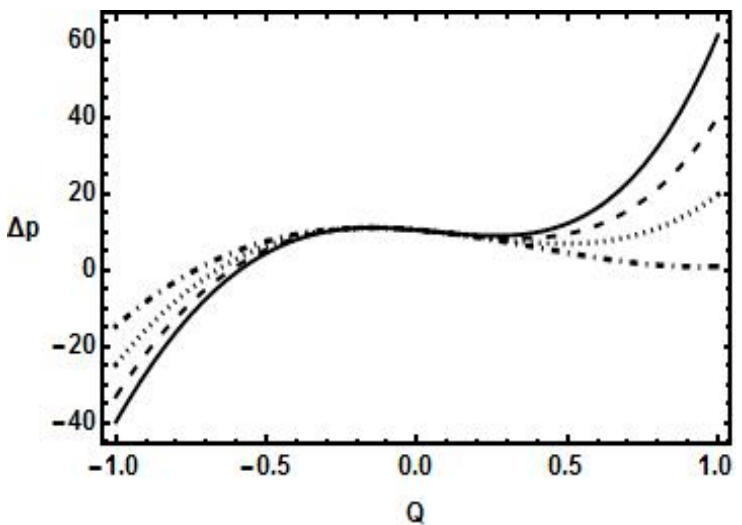

Figure 17. Pressure rise versus $Q$ for $R$.

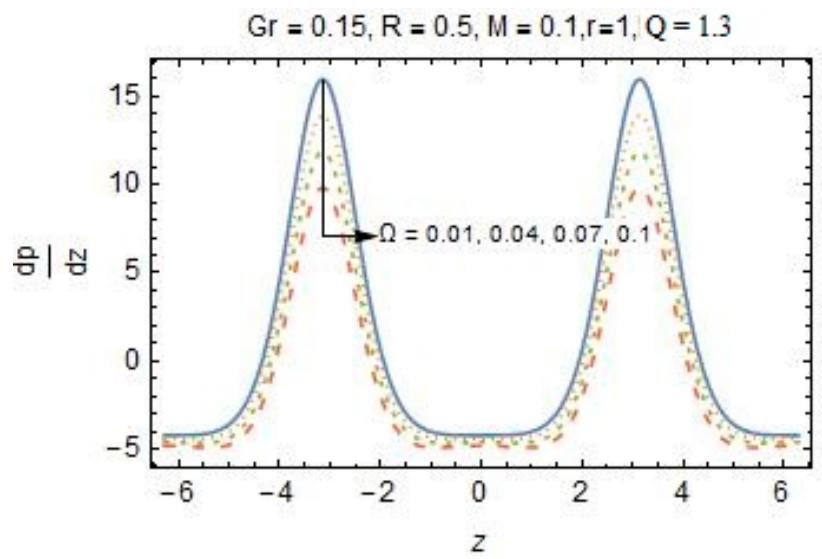

Figure 18. Pressure gradient for $\Omega$. 


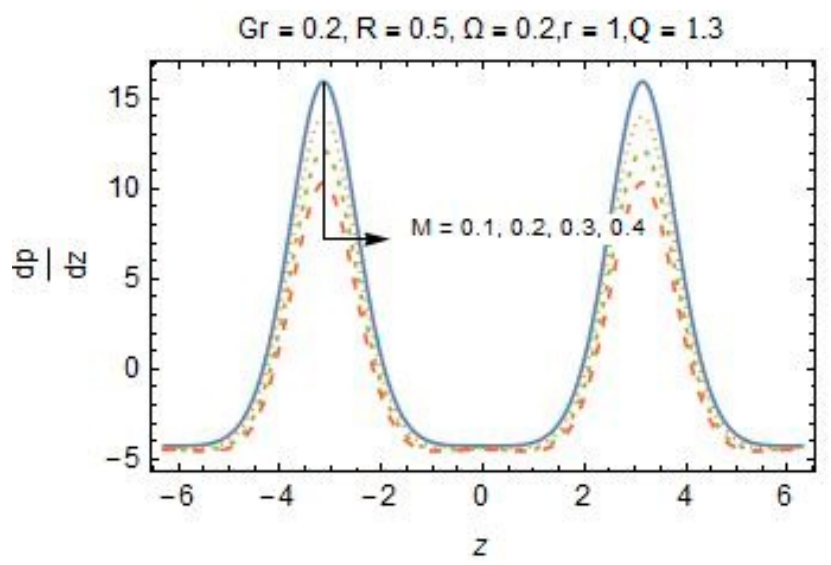

Figure 19. Pressure gradient for $M$.

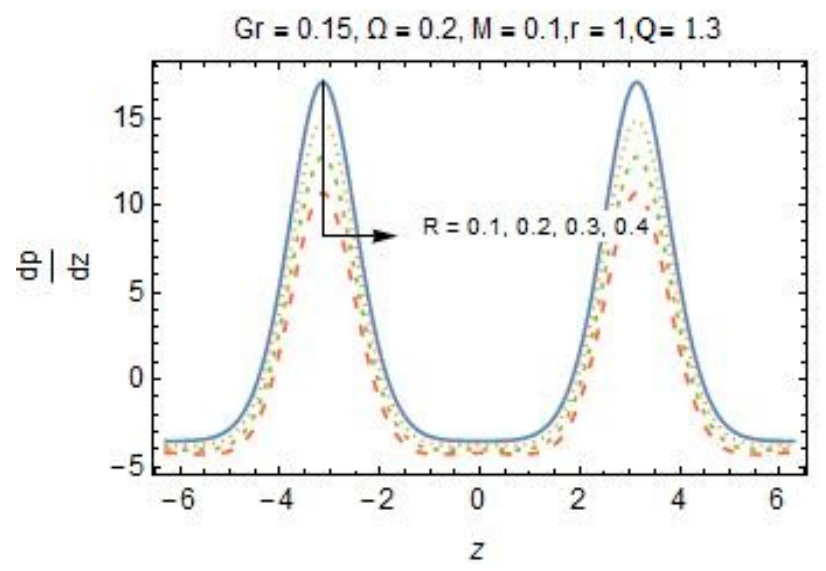

Figure 20. Pressure gradient for $R$.

Trapping is a significant observable fact, whereby a bolus is transported with the wave speed and then a trapped bolus pressed forward along metachronical waves. These configurations are plotted in Figures 22-25 for different values of sundry parameters with panels $(a)-(d)$ which inspect the ciliary-induced peristaltic flow pattern in the annulus. In general, the shape of streamlines is similar to the wave moving parallel to the walls of the tube. Under specific conditions, streamlines split and form a bolus which moves and circulates along the channel. The setup for the magnetic Reynolds number $(R)$ is explained in Figure 22 for $M=1.5, G r=0.8, Q=2, \varepsilon=0.2$. Higher values of $\mathrm{R}$ yield oscillatory motion of the fluid, and therefore a confined bolus decreases in size. Figure 23 depicts the behavior of streamlines for $M=1.5, R=2, Q=2, \varepsilon=0.2$ and it is perceived that with an increment in values of $G r$, the confined bolus is shrinked moving towards the boundary of external tube and finally disappear due to temperature distribution caused by buoyancy forces. A similar formation of the flow pattern against rising Hartmann number is explored in Figure 24 with $\mathrm{Gr}=0.8, \mathrm{R}=2, \mathrm{Q}=2, \varepsilon=0.2$. Physically, enhancement in magnitude of M augments fluid velocity which opposes trapping. This is in view of the fact that the magnitude of the amplitude ratio parameter $(\varepsilon)$ indicates the length of cilia and the increment in values of $\varepsilon$ enlarges cilia. The trapped bolus grows in size and circulates speedily as noticed in Figure 25. Thus, the presence of cilia favors trapping. 


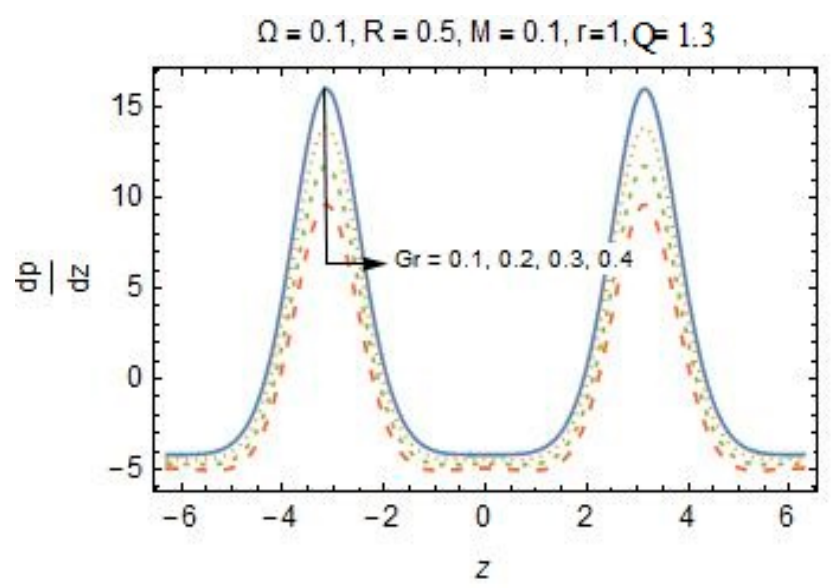

Figure 21. Pressure gradient for $G r$.

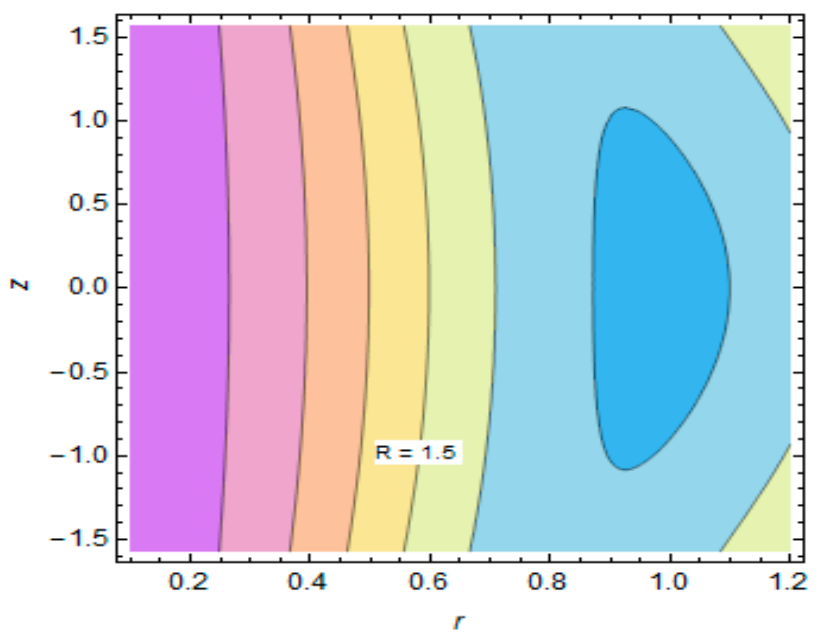

(a)

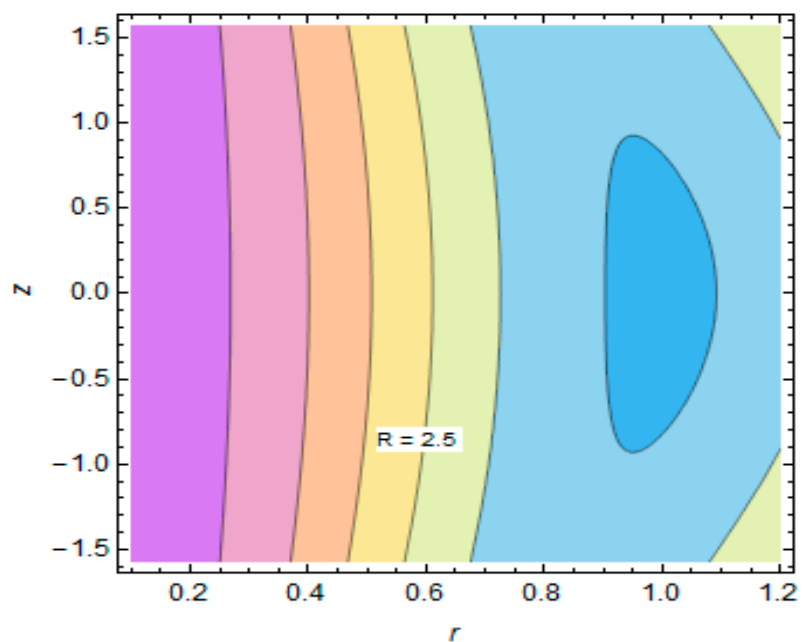

(b)

Figure 22. Cont. 


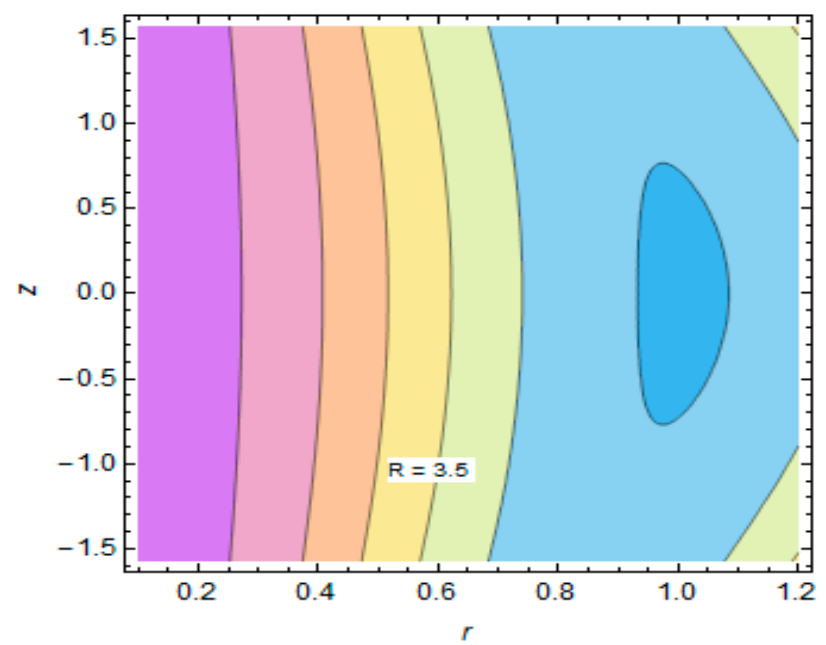

(c)

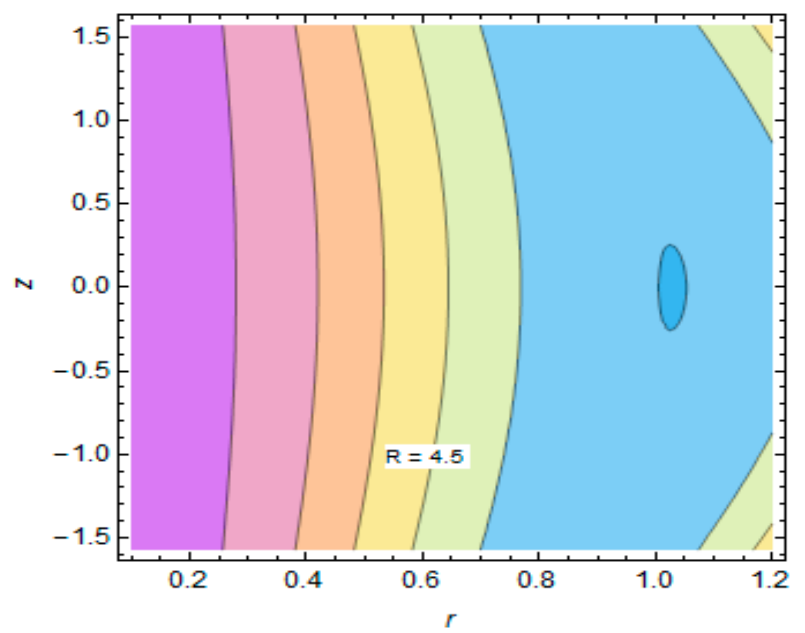

(d)

Figure 22. Behavior of streamlines for different values of magnetic Reynold number (a-d).

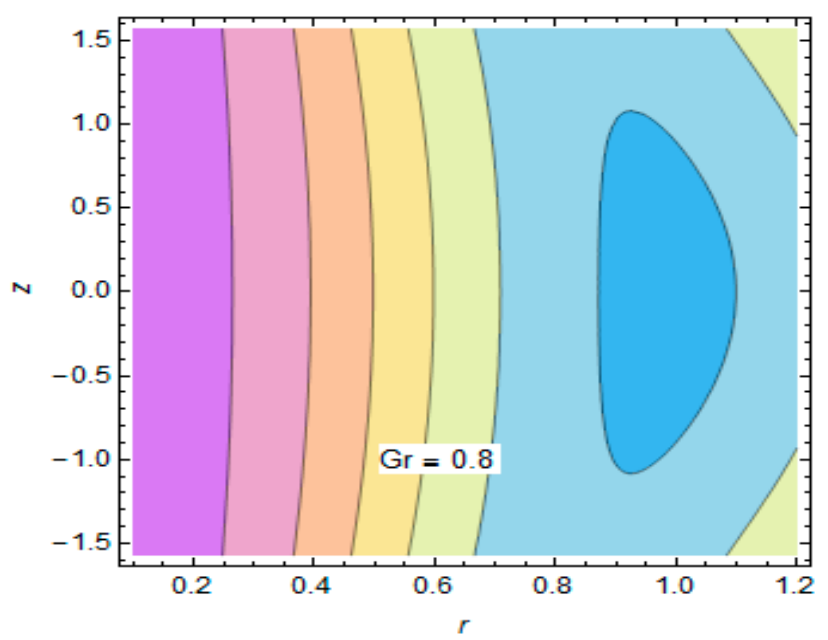

(a)

Figure 23. Cont. 


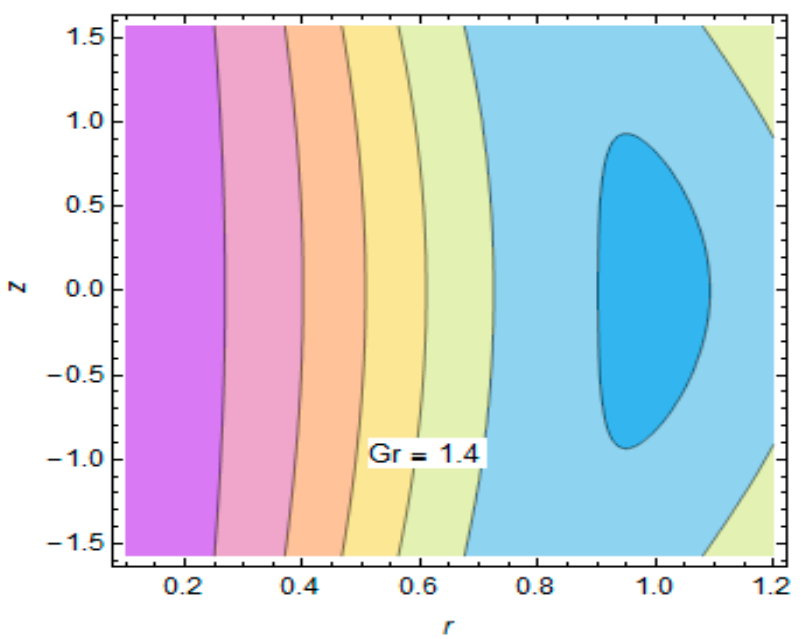

(b)

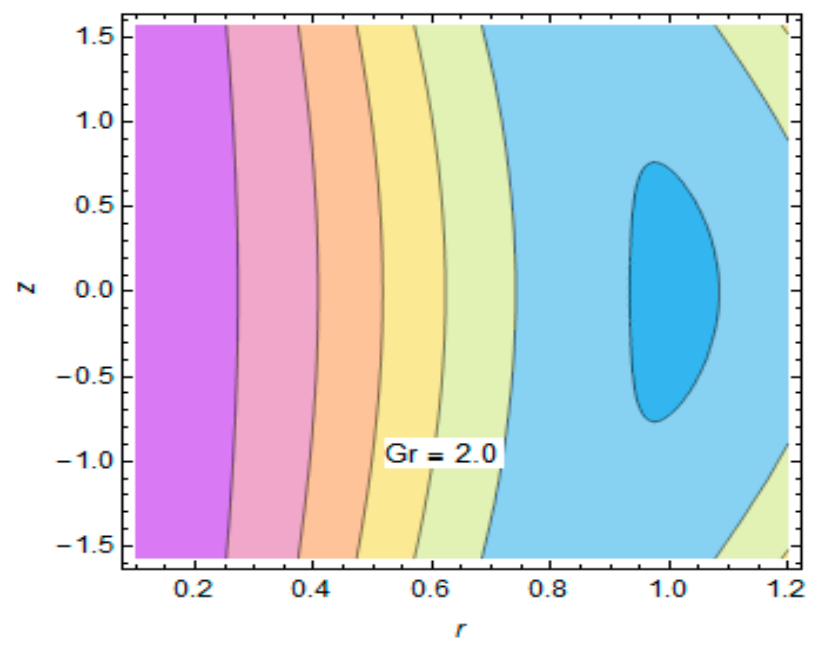

(c)

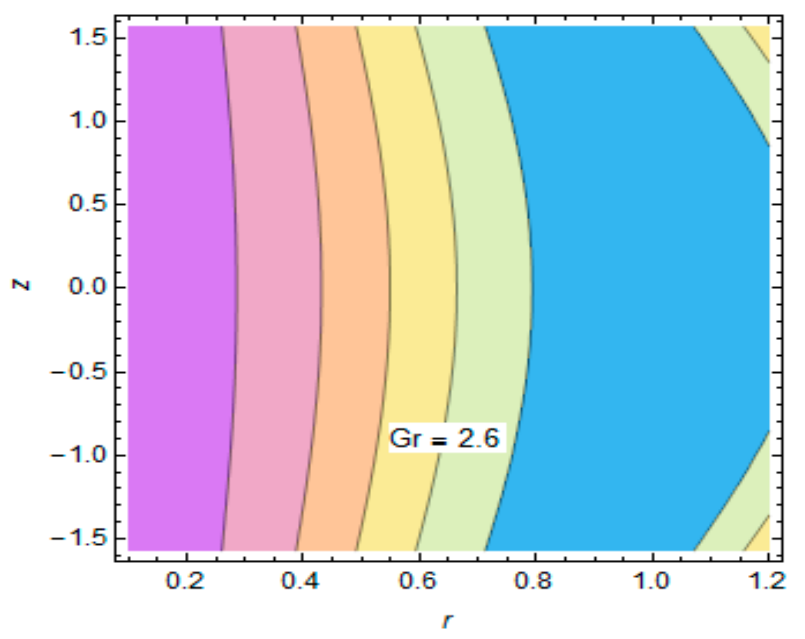

(d)

Figure 23. Behavior of streamlines for different values of Grashof number (a-d). 


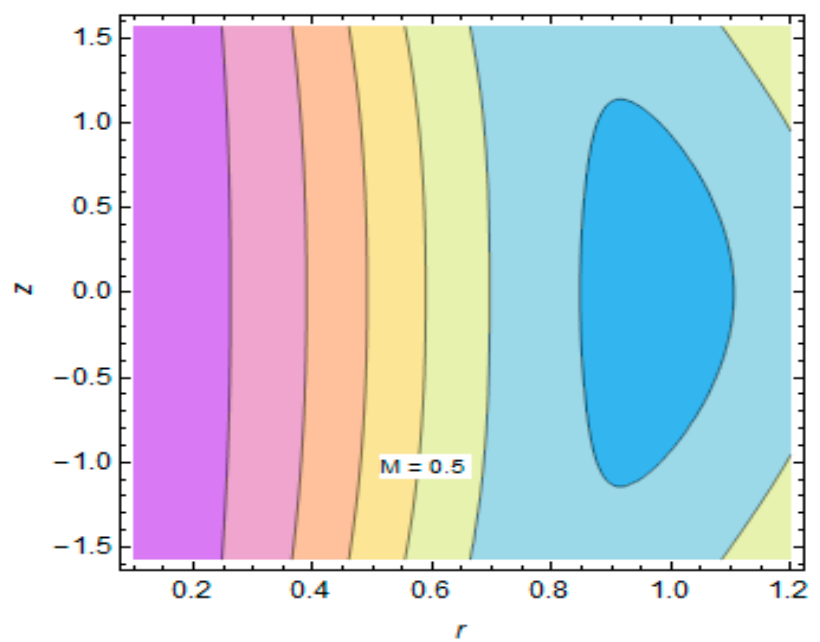

(a)

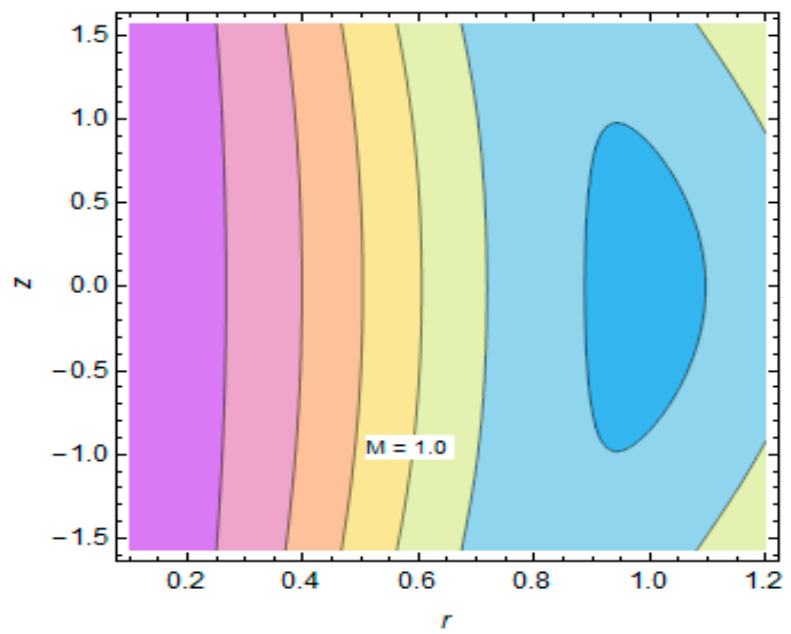

(b)

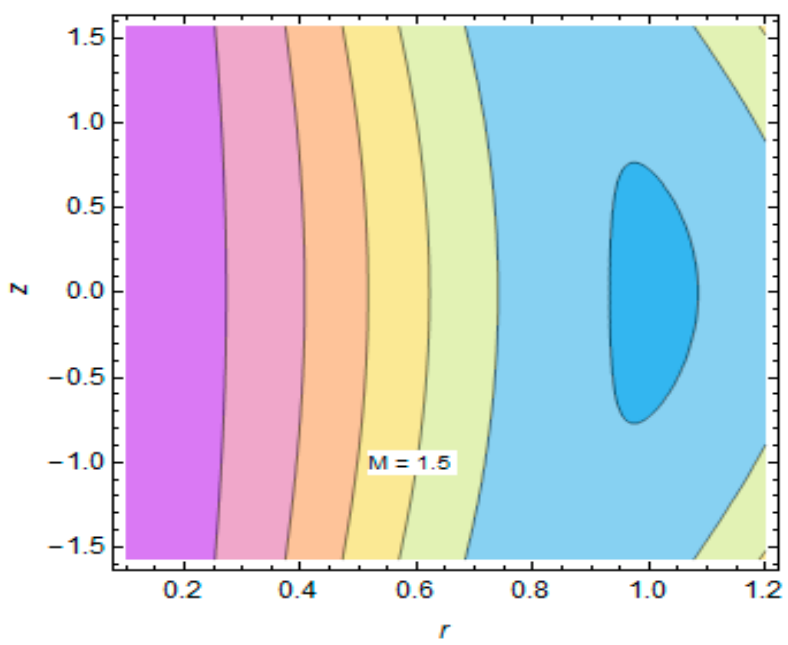

(c)

Figure 24. Cont. 


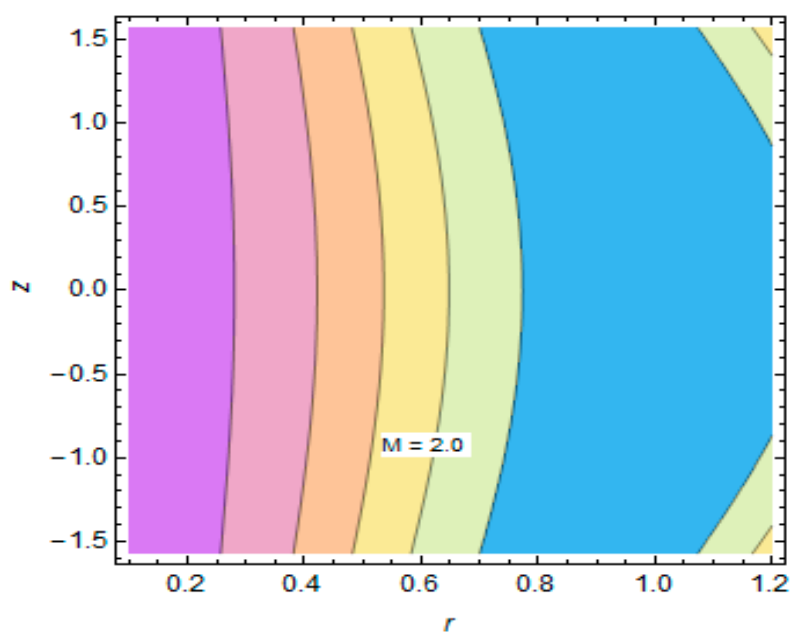

(d)

Figure 24. Behavior of streamlines for different values of Hartmann number (a-d).

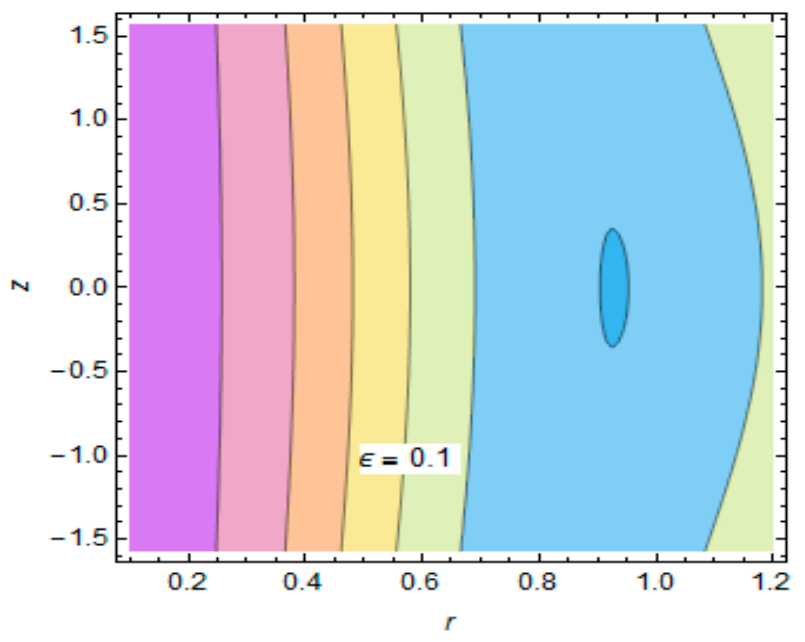

(a)

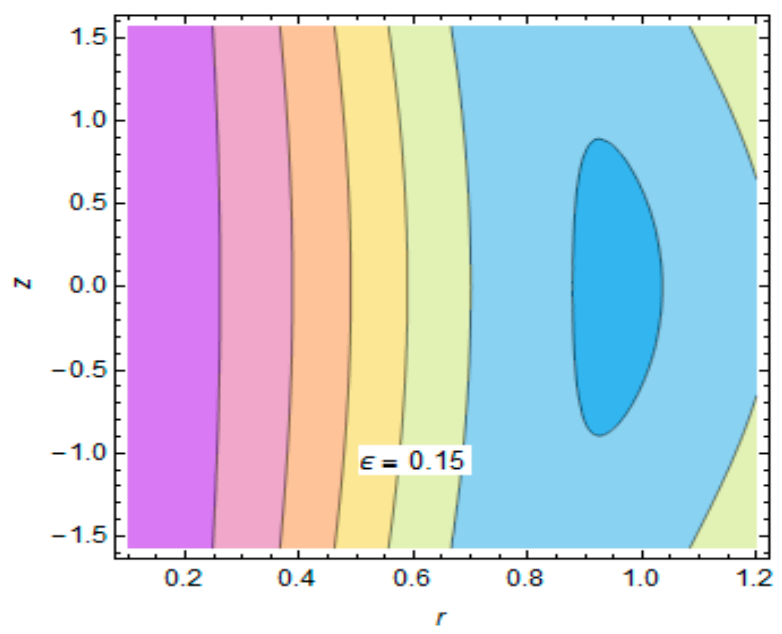

(b)

Figure 25. Cont. 


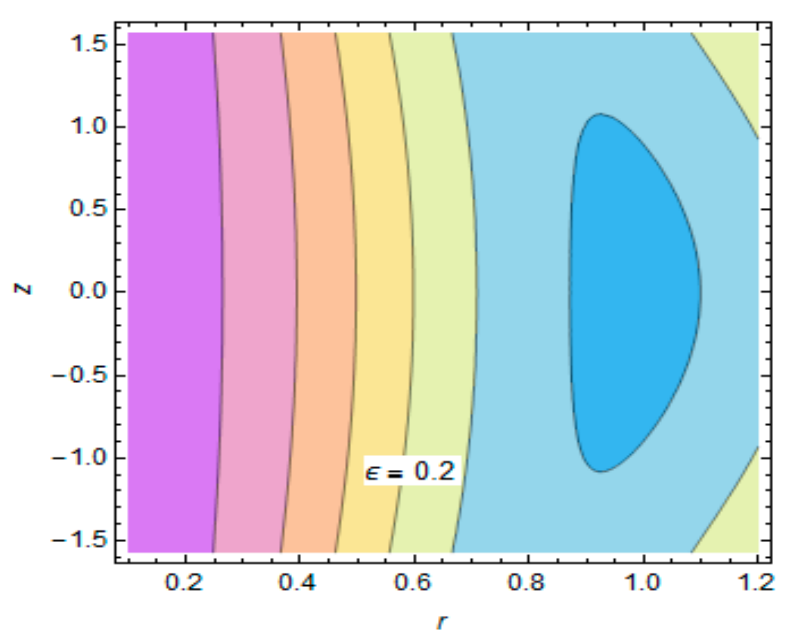

(c)

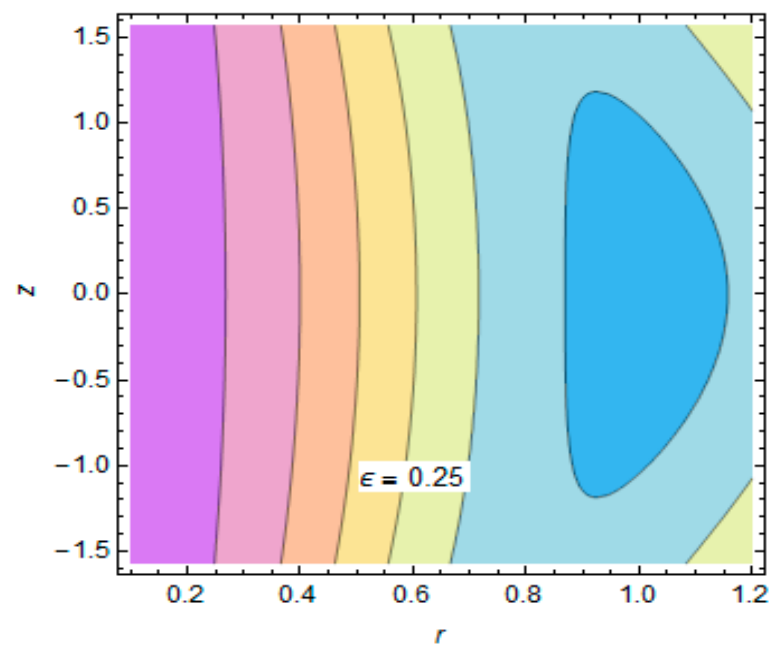

(d)

Figure 25. Behaviorof streamlines for different values of amplitude ratio (a-d).

Experiment-based numerical values and mathematical formulas for thermophysical characteristics of the hybrid nanofluid are expressed in Tables 1 and 2. Furthermore, the impact of engrossing parameters towards velocity and temperature profiles are presented in tabular form as shown in Tables 3 and 4. Table 3 shows that for small values of $r$, velocity decreases gradually but an increasing behavior is observed for larger radial distance against $M$ and $R$. A conflicting behavior of the temperature profile towards $R$ and $G r$ is depicted in Table 4. Additionally, the behaviors of velocity, temperature and magnetic induction profiles for variation in radial distance are examined and results are portrayed in Table 5. All the variations are examined for $M=4, R=2, G r=2.5, \Omega=4, Q=2, z=1, \varepsilon=0.2$.

Table 1. Numerical values of thermal characteristics of nanomaterials and base fluid at $25^{\circ} \mathrm{C}[9,12]$.

\begin{tabular}{cccc}
\hline Properties $\backslash$ Constituents & $\mathbf{H}_{\mathbf{2}} \mathbf{O}$ & $\mathbf{A g}$ & $\mathbf{T i O}_{\mathbf{2}}$ \\
\hline Density, $\rho\left(\mathrm{kg} / \mathrm{m}^{3}\right)$ & 997 & 10,500 & 4250 \\
Specific heat, $C_{p}(\mathrm{~J} / \mathrm{kg} \mathrm{K})$ & 4179 & 235 & 686.2 \\
Thermal conductivity, $\kappa(\mathrm{W} / \mathrm{m} \mathrm{K})$ & 0.613 & 429 & 8.95 \\
Thermal expansion coefficient, $\beta$ & 21 & 1.89 & 0.9 \\
$\left(10^{-5} \mathrm{~m} /(\mathrm{mK})\right)$ & & & \\
\hline
\end{tabular}


In addition, validation of existing results is examined by comparing them with those of Nadeem and Sadaf [50] in which an exact solution of a Newtonian $\mathrm{Cu} /$ blood nanofluid in the absence of magnetic induction has been studied. Table 6 shows that the two results are in good agreement. (See Table 6).

Table 2. Experimental relations for thermophysical characteristics of hybrid nanofluid $[9,10]$.

\begin{tabular}{|c|c|}
\hline Properties & Hybrid Nanofluid \\
\hline Density & $\rho_{\mathrm{hnf}}=\rho_{\mathrm{f}}\left(1-\varphi_{2}\right)\left[\left(1-\varphi_{1}\right)+\varphi_{1}\left(\frac{\rho_{\mathrm{s}_{1}}}{\rho_{\mathrm{f}}}\right)\right]+\varphi_{2} \rho_{\mathrm{s}_{2}}$ \\
\hline Heat Capacity & $\left(\rho \mathrm{c}_{\mathrm{p}}\right)_{\mathrm{hnf}}=\left(\rho \mathrm{c}_{\mathrm{p}}\right)_{\mathrm{f}}\left(1-\varphi_{2}\right)\left[\left(1-\varphi_{1}\right)+\varphi_{1}\left(\frac{\left(\rho \mathrm{c}_{\mathrm{p}}\right)_{\mathrm{s}_{1}}}{\left(\rho \mathrm{c}_{\mathrm{p}}\right)_{\mathrm{f}}}\right)\right]+\varphi_{2}\left(\rho \mathrm{c}_{\mathrm{p}}\right)_{\mathrm{s}_{2}}$ \\
\hline Viscosity & $\mu_{\mathrm{hnf}}=\frac{\mu_{\mathrm{f}}}{\left(1-\varphi_{1}\right)^{2.5}\left(1-\varphi_{2}\right)^{2.5}}$ \\
\hline Thermal Conductivity & $\begin{array}{c}\frac{\kappa_{\mathrm{hnf}}}{\kappa_{\mathrm{bf}}}=\frac{\kappa_{\mathrm{s}_{2}}+(\mathrm{s}-1) \kappa_{\mathrm{bf}}-(\mathrm{s}-1) \varphi_{2}\left(\kappa_{\mathrm{bf}}-\kappa_{\mathrm{s}_{2}}\right)}{\kappa_{\mathrm{s}_{2}}+(\mathrm{s}-1) \kappa_{\mathrm{bf}}+\varphi_{2}\left(\kappa_{\mathrm{bf}}-\kappa_{\mathrm{s}_{2}}\right)} \\
\text { where } \frac{\kappa_{\mathrm{bf}}}{\kappa_{\mathrm{f}}}=\frac{\kappa_{\mathrm{s}_{1}}+(\mathrm{s}-1) \kappa_{\mathrm{f}}-(\mathrm{s}-1) \varphi_{1}\left(\kappa_{\mathrm{f}}-\kappa_{\mathrm{s}_{1}}\right)}{\kappa_{\mathrm{s}_{1}}+(\mathrm{s}-1) \kappa_{\mathrm{f}}+\varphi_{1}\left(\kappa_{\mathrm{f}}-\kappa_{\mathrm{s}_{1}}\right)}\end{array}$ \\
\hline Thermal Expansion Coefficient & $(\rho \beta)_{\mathrm{hnf}}=(\rho \beta)_{\mathrm{f}}\left[\left(1-\phi_{1}-\phi_{2}\right)+\phi_{1}\left(\frac{(\rho \beta)_{\mathrm{s}_{1}}}{(\rho \beta)_{\mathrm{f}}}\right)\right]+\phi_{2}(\rho \beta)_{\mathrm{s}_{2}}$ \\
\hline
\end{tabular}

Table 3. Numerical values of velocity profile versus $r$ for variation in values of $M$ and $R$.

\begin{tabular}{ccccccc}
\hline $\mathbf{r}$ & \multicolumn{7}{c}{$\mathbf{w}(\mathbf{r})$} \\
\cline { 2 - 7 } & $\mathbf{M}=0.0$ & $\mathbf{M}=2.0$ & $\mathbf{M}=4.0$ & $\mathbf{R}=1.5$ & $\mathbf{R}=3.0$ & $\mathbf{R}=5$ \\
\hline 0.1 & -1.000000 & -1.000000 & -1.000000 & -1.000000 & -1.000000 & -1.000000 \\
0.3 & 2.916111 & 2.721028 & 2.141469 & 2.721303 & 2.720534 & 2.720410 \\
0.6 & 1.396253 & 1.358720 & 1.246153 & 1.358769 & 1.358632 & 1.358609 \\
0.9 & -0.352214 & -0.235930 & 0.109736 & -0.236095 & -0.235635 & -0.235561 \\
1.2 & -1.000013 & -1.000013 & -1.000013 & -1.000013 & -1.000013 & -1.000013 \\
\hline
\end{tabular}

Table 4. Numerical values of temperature profile versus $r$ for variation in values of $R$ and $G r$.

\begin{tabular}{ccccccc}
\hline $\mathbf{r}$ & \multicolumn{7}{c}{$\theta(\mathbf{r})$} \\
\cline { 2 - 7 } & $\mathbf{R}=2.0$ & $\mathbf{R}=4.0$ & $\mathbf{R}=6.0$ & $\mathbf{G r}=0.5$ & $\mathbf{G r}=2.0$ & $\mathbf{G r}=3.5$ \\
\hline 0.1 & 1.000000 & 1.000000 & 1.000000 & 1.000000 & 1.000000 & 1.000000 \\
0.3 & 1.074105 & 1.242672 & 1.298861 & 1.206081 & 1.140543 & 1.074070 \\
0.6 & 0.981608 & 1.122851 & 1.169931 & 1.185397 & 1.083984 & 0.981587 \\
0.9 & 0.501895 & 0.566682 & 0.588277 & 0.625917 & 0.564191 & 0.501894 \\
1.2 & 0.000000 & 0.000000 & 0.000000 & 0.000000 & 0.000000 & 0.000000 \\
\hline
\end{tabular}

Table 5. Variation in flow profiles for variation in radial distance $r$.

\begin{tabular}{cccc}
\hline $\mathbf{r}$ & Velocity & Temperature & Induced Magnetic Field \\
\hline 0.1 & -0.999999 & 1.000000 & 9.468376 \\
0.15 & 1.060587 & 0.965941 & 6.306623 \\
0.2 & 1.943109 & 0.975023 & 4.723305 \\
0.25 & 2.349953 & 0.999968 & 3.771855 \\
0.3 & 2.515741 & 1.028599 & 3.136419 \\
0.35 & 2.541556 & 1.054529 & 2.681561 \\
0.4 & 2.478507 & 1.074105 & 2.339547 \\
0.45 & 2.355582 & 1.085138 & 2.072744 \\
0.5 & 2.1907886 & 1.086309 & 1.858574 \\
0.55 & 1.9962259 & 1.076840 & 1.682671 \\
0.6 & 1.7806156 & 1.056315 & 1.535457 \\
0.65 & 1.5506610 & 1.024567 & 1.410307 \\
0.7 & 1.3118123 & 0.981608 & 1.302488 \\
\hline
\end{tabular}


Table 5. Cont.

\begin{tabular}{cccc}
\hline $\mathbf{r}$ & Velocity & Temperature & Induced Magnetic Field \\
\hline 0.75 & 1.0687020 & 0.927579 & 1.208531 \\
0.8 & 0.8253723 & 0.862717 & 1.125837 \\
0.85 & 0.5853391 & 0.787332 & 1.052418 \\
0.9 & 0.3514943 & 0.701789 & 0.986730 \\
0.95 & 0.1257983 & 0.606497 & 0.927553 \\
0.1 & -0.0913227 & 0.501895 & 0.873915 \\
1.05 & -0.3020293 & 0.388449 & 0.825024 \\
1.1 & -0.5127976 & 0.266646 & 0.780240 \\
1.15 & -0.7371672 & 0.136990 & 0.739028 \\
1.2 & -1.000013 & 0.000000 & 0.700945 \\
\hline
\end{tabular}

Table 6. Comparison of velocity with those of Nadeem and Sadaf [50] for $\mathrm{n}=1, \phi_{2}=0, \mathrm{M}=$ 0 and $\mathrm{E}=0$.

\begin{tabular}{ccccccc}
\hline \multirow{2}{*}{$\mathbf{r}$} & \multicolumn{6}{c}{$\mathbf{w}(\mathbf{r})=\frac{1}{\mathbf{r}} \frac{\partial \psi}{\partial \mathbf{r}}$} \\
\cline { 2 - 7 } & \multicolumn{2}{c}{$\mathbf{G r}=1.0$} & \multicolumn{2}{c}{$\mathbf{G r}=2.0$} & \multicolumn{2}{c}{$\mathbf{G r}=3.0$} \\
\cline { 2 - 7 } & Existing & [46] & Existing & {$[46]$} & Existing & {$[46]$} \\
\hline 0.1 & -1.000000 & -1.000000 & -1.000000 & -0.000000 & -1.000000 & -1.000000 \\
0.17 & -0.717905 & -0.717905 & -0.702637 & -0.702637 & -0.687369 & -0.687369 \\
0.24 & -0.559148 & -0.559157 & -0.539095 & -0.539095 & -0.519033 & -0.519033 \\
0.31 & -0.465611 & -0.465615 & -0.445894 & -0.445894 & -0.426172 & -0.426172 \\
0.38 & -0.415011 & -0.415014 & -0.398441 & -0.398441 & -0.381868 & -0.381868 \\
0.45 & -0.396309 & -0.396313 & -0.384359 & -0.384359 & -0.372405 & -0.372405 \\
0.52 & -0.403142 & -0.403151 & -0.396393 & -0.396393 & -0.389636 & -0.389636 \\
0.59 & -0.431481 & -0.431483 & -0.429839 & -0.429839 & -0.428195 & -0.428195 \\
0.66 & -0.478539 & -0.478546 & -0.481408 & -0.481408 & -0.48427 & -0.48427 \\
0.73 & -0.542336 & -0.542343 & -0.54867 & -0.54867 & -0.554997 & -0.554997 \\
0.80 & -0.621365 & -0.621371 & -0.629747 & -0.629747 & -0.638123 & -0.638123 \\
0.87 & -0.714447 & -0.714452 & -0.723131 & -0.723131 & -0.73181 & -0.73181 \\
0.94 & -0.820564 & -0.820638 & -0.827574 & -0.827574 & -0.834509 & -0.834509 \\
1.01 & -0.939132 & -0.939145 & -0.942016 & -0.942016 & -0.944887 & -0.944887 \\
1.04382 & -1.00061 & -1.00061 & -1.00061 & -1.00061 & -1.00061 & -1.00061 \\
\hline
\end{tabular}

\section{Conclusions}

This study incorporates the effects of electromagnetic induction on a rheological model of a hybrid nanofluid in ciliary-induced peristalsis through an endoscope. The major findings are summarized as:

* Velocity of the hybrid nanofluid reduces for M and Gr near the endoscope but it increases near the external peristaltic tube having a ciliary surface due to a decreasing pressure gradient, even in creeping flow condition as observed from 2-D and 3-D plots. These results show that buoyancy effects are more prominent near the peristaltic tube and magnetic induction enhances peristalsis in presence of $\mathrm{Ag}-\mathrm{TiO}_{2}$ nanohybrids with $0.2 \%$ concentration.

- The magnetic induction profile displays a similar behavior as that of velocity towards the magnetic Reynolds number. An increase in values of $\mathrm{R}$ upgrades the flow rate and hence it is concluded that velocity and induced magnetic field relatively generate elastic oscillations. Consequently, fluid having hybrid nanoparticles can deeply interact with tumors and efficiently deliver drugs to specified section.

* The temperature of hybrid nanofluid depicts a decreasing behavior for Gr while a conflicting trend is seen for $\mathrm{R}$. This trend of temperature increase of the fluid will be helpful in the removal of a cancer tumor and abnormal cells without affecting healthy parts within the body during an endoscopy. 
* The behavior of the pressure rise for different parameters show that the pressure rise declines in the co-pumping region whereas it is enhanced in the pumping and free-pumping regions. Pumping rate increases for increment in radius ratio parameter which is favorable for accurate endoscopic imaging.

* The pressure gradient decreases throughout the length of the endoscope close to the ciliated peristaltic tube for $r_{2}=1$.

* Numerical values of velocity and temperature against embedding parameters explore a similar behavior as noticed in graphs. Flow profiles towards variation in radial distance are examined which satisfy the conditions of the problem.

* The presence of cilia shows a dominant effect on the behavior of the flow variables. In most cases, the sensitive interior surface of organs may be protected due to cilia as they assist velocity near the peristaltic tube.

- The peristaltic flow pattern due to ciliary activity for different parameters is displayed via streamline configuration and a reduction in the size of the trapped bolus is observed towards $R$, $M$ and $G r$ but conversely enlarges for $\varepsilon$.

* The present work appears to be the first attempt in the literature dealing with the effects of electromagnetic induction on peristaltic transport and the heat transfer of non-Newtonian hybrid nanofluid through a ciliated tube inserted by an endoscope. Additional developments and characteristics of the problem can be examined.

* Results for Newtonian nanofluid [50] can be obtained in a limiting case.

Author Contributions: Conceptualization, M.A. and Z.S.; methodology, M.A., Z.S., P.K. and N.P.; software, A.A., P.K. and P.T.; validation, P.T. and and Z.S.; formal analysis, M.A., A.A., P.K. and N.P.; investigation, Z.S., P.K. and A.A.; resources, P.K. and P.T.; data curation, M.A.; writing-original draft preparation, M.A., Z.S. and A.A.; writing-review and editing, A.A., H.u.R.; visualization, Z.S. and H.u.R.; supervision, P.K. and A.A.; project administration, P.K., P.T. and Z.S.; funding acquisition, P.K., P.T. and Z.S. All authors have read and agreed to the published version of the manuscript.

Funding: This research was funded by the Center of Excellence in Theoretical and Computational Science (TaCS-CoE), KMUTT.

Acknowledgments: This research is supported by Postdoctoral Fellowship from King Mongkut's University of Technology Thonburi (KMUTT), Thailand.

Conflicts of Interest: The authors declare that they have no competing interests.

\section{Nomenclature}

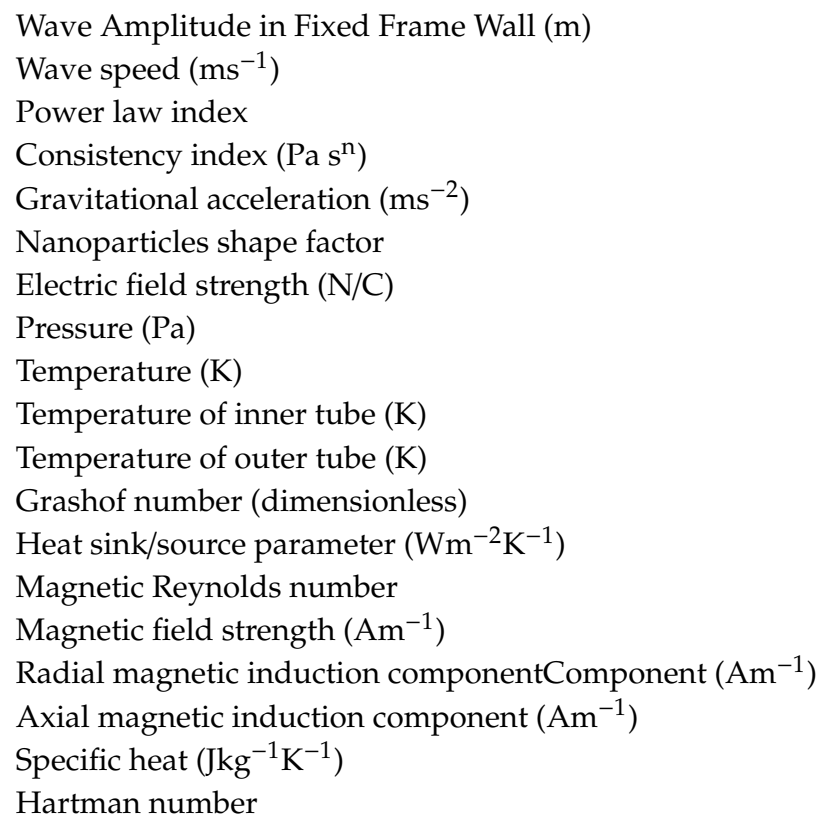


U Radial velocity component $\left(\mathrm{ms}^{-1}\right)$

$\mathrm{W} \quad$ Axial velocity component $\left(\mathrm{ms}^{-1}\right)$

\section{Greek Symbol}

$\rho$

Density $\left(\mathrm{kgm}^{-3}\right)$

Electric conductivity $(\mathrm{S} / \mathrm{m})$

Magnetic force function $\left(\mathrm{A}^{2} \mathrm{~m}^{-1}\right)$

Stream function $\left(\mathrm{m}^{2} \mathrm{~s}^{-1}\right)$

Thermal expansion coefficient $\left(\mathrm{K}^{-1}\right)$

Wavelength (m)

Wave number (dimensionless)

Magnetic Diffusivity $\left(\mathrm{m}^{2} \mathrm{~s}^{-1}\right)$

Dynamic viscosity $\left(\mathrm{kgm}^{-1} \mathrm{~s}^{-1}\right)$

Wave amplitude in moving frame (m)

Thermal conductivity $\left(\mathrm{Wm}^{-1} \mathrm{~K}^{-1}\right)$

Dimensionless heat source/sink parameter

Rate of deformation tensor $\left(\mathrm{s}^{-1}\right)$

Shear stress $(\mathrm{Pa})$

\section{$\alpha \quad$ Measure of eccentricity}

\section{Subscript}

hnf Hybrid Nanofluid

f Base fluid

$s_{1} \quad$ Solid nano particles of $\mathrm{Ag}$

$s_{2} \quad$ Solid nano particles of $\mathrm{TiO}_{2}$

\section{Appendix A}

$$
\begin{aligned}
& \psi_{0}(r)=\left(-\frac{-F r_{1}^{3}+3 F r_{1}^{2} r_{2}+3 F r_{1} r_{2}^{2}-4 r_{1}^{3} r_{2}^{2}-F r_{2}^{3}+4 r_{1}^{2} r_{2}^{3}-4 \pi r_{1}^{3} r_{2}^{2} \alpha \delta \varepsilon \cos (2 \pi z)+4 \pi r_{1}^{2} r_{2}^{3} \alpha \delta \varepsilon \cos (2 \pi z)}{2\left(r_{1}-r_{2}\right)^{3}}\right)+ \\
& \left(-\frac{r_{1} r_{2}\left(-6 F+3 r_{1}^{2}-3 r_{2}^{2}+2 \pi r_{1}^{2} \alpha \delta \varepsilon \cos (2 \pi z)+2 \pi r_{1} r_{2} \alpha \delta \varepsilon \cos (2 \pi z)-4 \pi r_{2}^{2} \alpha \delta \varepsilon \cos (2 \pi z)\right)}{\left(r_{1}-r_{2}\right)^{3}}\right) r \\
& +\left(-\frac{3 F r_{1}-r_{1}^{3}+3 F r_{2}-3 r_{1}^{2} r_{2}+3 r_{1} r_{2}^{2}+r_{2}^{3}-4 \pi r_{1}^{2} r_{2} \alpha \delta \varepsilon \cos (2 \pi z)+2 \pi r_{1} r_{2}^{2} \alpha \delta \varepsilon \cos (2 \pi z)+2 \pi r_{2}^{3} \alpha \delta \varepsilon \cos (2 \pi z)}{\left(r_{1}-r_{2}\right)^{3}}\right) r^{2} \\
& +\left(-\frac{-2 F+r_{1}^{2}-r_{2}^{2}+2 \pi r_{1} r_{2} \alpha \delta \varepsilon \cos (2 \pi z)-2 \pi r_{2}^{2} \alpha \delta \varepsilon \cos (2 \pi z)}{\left(r_{1}-r_{2}\right)^{3}}\right) r^{3}, \\
& \phi_{0}(r)=\frac{1}{\left(r_{1}-r_{2}\right)}\left(r_{1}-r\right), \theta_{0}(r)=\frac{1}{\left(r_{1}-r_{2}\right)}\left(-r_{2}+r\right), \\
& N_{1}[\psi(r, \gamma), \phi(r, \gamma), \theta(r, \gamma)] \\
& =-\frac{1}{r^{2}}\left(-\frac{1}{r^{2}} \frac{d \psi}{d r}+\frac{1}{r} \frac{d^{2} \psi}{d r^{2}}\right)^{2}+\frac{2}{r}\left(-\frac{1}{r^{2}} \frac{d \psi}{d r}+\frac{1}{r} \frac{d^{2} \psi}{d r^{2}}\right)\left(\frac{2}{r^{3}} \frac{d \psi}{d r}-\frac{2}{r^{2}} \frac{d^{2} \psi}{d r^{2}}+\frac{1}{r} \frac{d^{3} \psi}{d r^{3}}\right) \\
& +2\left(\frac{2}{r^{3}} \frac{d \psi}{d r}-\frac{2}{r^{2}} \frac{d^{2} \psi}{d r^{2}}+\frac{1}{r} \frac{d^{3} \psi}{d r^{3}}\right)^{2}+2\left(-\frac{1}{r^{2}} \frac{d \psi}{d r}+\frac{1}{r} \frac{d^{2} \psi}{d r^{2}}\right)\left(-\frac{6}{r^{4}} \frac{d \psi}{d r}+\frac{6}{r^{3}} \frac{d^{2} \psi}{d r^{2}}-\frac{3}{r^{2}} \frac{d^{3} \psi}{d r^{3}}+\frac{1}{r} \frac{d^{4} \psi}{d r^{4}}\right) \\
& +M^{2}\left(-\frac{1}{r^{2}} \frac{d \psi}{d r}+\frac{1}{r} \frac{d^{2} \psi}{d r^{2}}\right)-A_{1} G r \frac{d \theta}{d r} \\
& N_{2}[\psi(r, \gamma), \phi(r, \gamma), \theta(r, \gamma)]=E-\frac{1}{r} \frac{d \psi}{d r}-\frac{1}{R_{m}}\left(-\frac{1}{r^{2}} \frac{d \phi}{d r}+\frac{1}{r} \frac{d^{2} \phi}{d r^{2}}\right), \\
& N_{3}[\psi(r, \gamma), \phi(r, \gamma), \theta(r, \gamma)]=\frac{1}{r} \frac{d \theta}{d r}+\frac{d^{2} \theta}{d r^{2}}+\frac{\Omega}{A_{2}} . \\
& R_{m}^{1}(r, \gamma)=2 \sum_{k=0}^{m-1}\left(\frac{1}{r^{2}} \psi^{(i v)}{ }_{m-1-k} \psi^{\prime \prime}{ }_{k}-\frac{1}{r^{3}} \psi^{(i v)}{ }_{m-1-k} \psi_{k}^{\prime}\right)+2 \sum_{k=0}^{m-1}\left(\frac{1}{r^{2}} \psi^{\prime \prime \prime}{ }_{m-1-k} \psi^{\prime \prime \prime}{ }_{k}-\frac{6}{r^{3}} \psi^{\prime \prime \prime}{ }_{m-1-k} \psi_{k}{ }_{k}+\frac{6}{r^{4}} \psi^{\prime \prime \prime}{ }_{m-1-k} \psi_{k}^{\prime}\right) \\
& +15 \sum_{k=0}^{m-1}\left(-\frac{2}{r^{5}} \psi_{m-1-k}^{\prime \prime} \psi_{k}^{\prime}+\frac{1}{r^{4}} \psi^{\prime \prime}{ }_{m-1-k} \psi_{k}^{\prime \prime}+\frac{1}{r^{3}} \psi_{m-1-k}^{\prime} \psi_{k}^{\prime}\right)+M^{2}\left(-\frac{1}{r^{2}} \psi^{\prime}+\frac{1}{r} \psi^{\prime \prime}\right)-A_{1} G r \theta^{\prime}, \\
& R_{m}^{2}(r, \gamma)=E-\frac{1}{r} \psi_{m-1}^{\prime}-\frac{1}{R_{m}}\left(-\frac{1}{r^{2}} \phi^{\prime}{ }_{m-1}+\frac{1}{r} \phi^{\prime \prime}{ }_{m-1}\right), \\
& R_{m}^{3}(r, \gamma)=r \theta^{\prime \prime}{ }_{m-1}+\theta^{\prime}{ }_{m-1}+r \frac{\Omega}{A_{2}} .
\end{aligned}
$$




\section{References}

1. Choi, S.U.S.; Eastman, J.A. Enhancing thermal conductivity of fluids with nanoparticles. In Proceedings of the 1995 International Mechanical Engineering Congress and Exhibition, San Francisco, CA, USA, 12-17 November 1995.

2. Awais, M.; Hayat, T.; Muqaddass, N.; Ali, A.; Awan, S.E. Nanoparticles and nonlinear thermal radiation properties in the rheology of polymeric material. Results Phys. 2018, 8, 1038-1045. [CrossRef]

3. Mehmood, A.; Zameer, A.; Ling, S.H.; Raja, M.A.Z. Design of neuro-computing paradigms for nonlinear nanofluidic system of MHD Jaffery-Hamel flow. J. Taiwan Inst. Chem. Eng. 2018, 91, 57-85. [CrossRef]

4. Shah, Z.; Sheikholeslami, M.; Kumam, P.; Shutaywi, M.; Thounthong, P. CFD simulation of water based hybrid nanofluid inside a porous enclosure employing Lorentz forces. IEEE Access 2019. [CrossRef]

5. Awan, S.E.; Khan, Z.A.; Awais, M.; Rehman, S.U.; Raja, M.A.Z. Numerical treatment for hydro-magnetic unsteady channel flow of nanofluid with heat transfer. Results Phys. 2018, 9, 1543-1554. [CrossRef]

6. Qureshi, I.H.; Nawaz, M.; Shehzad, A. Numerical study of dispersion of nanoparticles in magnetohydrodynamic liquid with Hall and ion slip currents. AIP Adv. 2019, 9, 025219. [CrossRef]

7. Hassan, M.; Faisal, A.; Ali, I.; Bhatti, M.M.; Yousaf, M. Effect of Cu-Ag hybrid nanoparticles on the momentum and thermal boundary layer flow in the wedge. Proc. Inst. Mech. Eng. Part E J. Process Mech. Eng. 2019. [CrossRef]

8. Shah, Z.; Alzahrani, E.O.; Alghamdi, W.; Ullah, M.Z. Influences of electrical MHD and Hall current on squeezing nanofluid flow inside rotating porous plates with viscous and joule dissipation effects. J. Therm. Anal. Calorim. 2020. [CrossRef]

9. Hussain, M.; Ellahi, R.; Zeeshan, A.; Bhatti, M.M. Analysis of natural convective of non-Newtonian fluid under the effects of nanoparticles of different materials. Proc. Inst. Mech. Eng. Part E J. Process Mech. Eng. 2019, 233, 643-652. [CrossRef]

10. Rashidi, M.M.; Mohebbi, R.; Ma, Y.; Yang, Z. MHD convective heat transfer of Ag-MgO/water hybrid nanofluid in a channel with active heaters and coolers. Int. J. Heat Mass Trans. 2019, 137, 714-772.

11. Nawaz, M.; Nazir, U. An enhancement in thermal performance of partially ionized fluid due to hybrid nano-structures exposed to magnetic field. AIP Adv. 2019, 9, 085024. [CrossRef]

12. Nguyen, V.T.; Vu, V.T.; Nguyen, T.H.; Nguyen, T.A.; Tran, V.K.; Nguyen-Tri, P. Antibacterial activity of TiO $2^{-}$ and $\mathrm{ZnO}$-decorated with silver nanoparticles. J. Compos. Sci. 2019, 3, 61. [CrossRef]

13. Li, R.; Chen, G.; Dong, G.; Sun, X. Controllable synthesis of nanostructured $\mathrm{TiO}_{2}$ by CTAB-assisted hydrothermal route. New J. Chem. 2014, 38, 4684-4689. [CrossRef]

14. Devi, L.G.; Kottam, N.; Murthy, B.N.; Kumar, S.G. Enhanced photocatalytic activity of transition metal ions $\mathrm{Mn}^{2+}, \mathrm{Ni}^{2+}$ and $\mathrm{Zn}^{2+}$ doped polycrystalline titania for the degradation of aniline blue under UV/solar light. J. Mol. Catal. A 2010, 328, 44-52. [CrossRef]

15. Benkhedda, M.; Boufendi, T.; Touahri, S. Laminar mixed convective heat transfer enhancement by using $\mathrm{Ag}-\mathrm{TiO}_{2} /$ water hybrid nanofluid in a heated horizontal annulus. Heat Mass. Trans. 2018, 54, $2799-2814$. [CrossRef]

16. Abrar, M.N.; Haq, R.U.; Awais, M.; Rashid, I. Entropy analysis in a cilia transport of nanofluid under the influence of magnetic field. Nucl. Eng. Technol. 2017, 49, 1680-1688. [CrossRef]

17. Awais, M.; Bukhari, U.; Ali, A.; Yasmin, H. Convective and peristaltic viscous fluid flow with variable viscosity. J. Eng. Phys. 2017, 26, 69-78. [CrossRef]

18. Engelmann, T.W. Zur Physiologie des Ureter. Archiv für die Gesamte Physiologie des Menschen und der Tiere 1869, 2, 243-293. [CrossRef]

19. Abbas, M.A.; Bai, Y.; Rashidi, M.M.; Bhatti, M.M. Application of drug delivery in megnetohydrodynamics peristaltic blood flow of nano fluid in a non-uniform channel. J. Mech. Med. Biol. 2016, 16, 1650052. [CrossRef]

20. Hayat, T.; Nawaz, S.; Alsaedi, A.; Rafiq, M. Mixed convective peristaltic flow of water based nanofluids with Joule heating and convective boundary conditions. PLoS ONE 2016, 11, e0153537. [CrossRef]

21. Maqbool, K.; Shaheen, S.; Siddiqui, A.M. Effects of nanoparticles on MHD flow of tangent hyperbolic fluid in a ciliated tube. Math. Biosci. Eng. 2019, 16, 2927-2941. [CrossRef]

22. Hayat, T.; Farooq, S.; Alsaedi, A.; Ahmad, B. Numerical analysis for radial MHD and mixed convection effects in peristalsis of non-Newtonian nanomaterial with zero mass flux condition. Results Phys. 2017, 7, 451-458. [CrossRef] 
23. Misra, J.C.; Pandey, S.K. Peristaltic flow of a multi-layered power-law fluid through a cylindrical tube. Int. J. Eng. Sci. 2001, 39, 387-402. [CrossRef]

24. Ahmad Farooq, A.; Shah, Z.; O Alzahrani, E. Heat Transfer Analysis of a Magneto-Bio-Fluid Transport with Variable Thermal Viscosity through a Vertical Ciliated Channel. Symmetry 2019, 11, 1240. [CrossRef]

25. Saeed, A.; Islam, S.; Dawar, A.; Shah, Z.; Kumam, P.; Khan, W. Influence of Cattaneo-Christov heat flux on MHD Jeffrey, Maxwell, and Oldroyd-B Nanofluids with Homogeneous-Heterogeneous reaction. Symmetry 2019, 11, 439. [CrossRef]

26. Ellahi, R.; Sait, S.M.; Shehzad, N.; Mobin, N. Numerical simulation and mathematical modeling ofElectro-Osmotic Couette-Poiseuille flow of MHD power-law nanofluid with entropy generation. Symmetry 2019, 11, 1038. [CrossRef]

27. Hayat, T.; Farooq, S.; Ahmad, B.; Alsaedi, A. Homogeneous-heterogeneous reactions and heat source/sink effects in MHD peristaltic flow of micropolar fluid with Newtonian heating in a curved channel. J. Mol. Liq. 2016, 223, 469-488. [CrossRef]

28. Bhatti, M.M.; Zeeshan, A.; Ellahi, R. Simultaneous effects of coagulation and variable magnetic field on peristaltically induced motion of Jeffrey nanofluid containing gyrotactic microorganism. Microvasc. Res. 2017, 110, 32-42. [CrossRef]

29. Rana, P.; Shukla, N. Entropy generation analysis for non-similar analytical study of nanofluid flow and heat transfer under the influence of aligned magnetic field. Alex. Eng. J. 2018, 57, 3299-3310. [CrossRef]

30. Shit, G.C.; Ranjit, N.K.; Sinha, A.; Roy, M. Effect of induced magnetic field on peristaltic transport of a micropolar fluid in the presence of slip velocity. Int. J. Appl. Math. Mech. 2014, 10, 81-107.

31. Noreen, S. Mixed convection peristaltic flow with slip conditions and induced magnetic field. Eur. Phys. J. Plus 2014, 129, 33. [CrossRef]

32. Noreen, S. Induced magnetic field effects on peristaltic flow in a curved channel. Zeitschrift für Naturforschung A 2015, 70, 3-9. [CrossRef]

33. Jha, B.K.; Aina, B. Effect of induced magnetic field on MHD mixed convection flow in vertical microchannel. Int. J. Appl. Mech. Eng. 2017, 22, 567-582. [CrossRef]

34. Eifler, A.C.; Thaxton, C.S. Nanoparticle therapeutics: FDA approval, clinical trials, regulatory pathways and case study. Methods Mol. Biol. 2011, 726, 325-338.

35. Ellahi, R.; Zeeshan, A.; Hussain, F.; Abbas, T. Study of shiny film coating on multi-fluid flows of a rotating disk suspended with nano-sized silver and gold particles: A comparative analysis. Coatings 2018, 8, 422. [CrossRef]

36. Akbar, N.S.; Butt, A.W. Physiological transportation of Casson fluid in a plumb duct. Commun. Phys. 2015, 63, 347-352.

37. Dawar, A.; Shah, Z.; Kumam, P.; Khan, W.; Islam, S. Influence of MHD on thermal behavior of Darcy-Forchheimer nanofluid thin film flow over a nonlinear stretching disc. Coatings 2019, 9, 446. [CrossRef]

38. Ellahi, R.; Zeeshan, A.; Hussain, F.; Abbas, T. Thermally charged MHD bi-phase flow coatings with non-Newtonian nanofluid and Hafnium particles through slippery walls. Coatings 2019, 9, 300. [CrossRef]

39. Hayat, T.; Momoniat, E.; Mahomed, F.M. Endoscope effects on MHD peristaltic flow of a power law fluid. Math. Probl. Eng. 2006, 2006, 84276. [CrossRef]

40. Hayat, T.; Ali, N. Effects of an endoscope on peristaltic flow of a micropolar fluid. Math. Comput. Model. 2008, 48, 721-733. [CrossRef]

41. Nadeem, S.; Akbar, N.S. Influence of temperature dependent viscosity on peristaltic transport of a Newtonian fluid: Application of an endoscope. Appl. Math. Comput. 2010, 216, 3606-3619. [CrossRef]

42. Rathod, V.P.; Asha, S.K. Effects of magnetic field and an endoscope on peristaltic motion. J. Appl. Math. 2011, 2011, 148561. [CrossRef]

43. Bhatti, M.M.; Zeeshan, A. Study of variable magnetic field and endoscope on peristaltic blood flow of particle-fluid suspension through an annulus. Biomed. Eng. Lett. 2016, 6, 242-249. [CrossRef]

44. Ramesh, K.; Devakar, M. The effects of endoscope and heat transfer on the peristaltic flow of a second grade fluid in an inclined tube. J. Mech. Med. biol. 2016, 16, 1650057. [CrossRef]

45. Ramesh, K.; Devakar, M. Magnetohydrodynamic peristaltic flow of Pseudoplastic fluid in a vertical asymmetic channel through porous medium with heat and mass transfer. Iran. J. Sci. Technol.-Sci. 2017, 41, 257-272. [CrossRef] 
46. Abdellateef, A.I.; UlHaque, S.Z. Peristaltic flow of Newtonian nanofluid through an inclined annulus cylinder. Eur. J. Pure Appl. Math. 2016, 9, 266-276.

47. Ramesh, K.; Devakar, M. Effect of endoscope on the peristaltic transport of a couple stress fluid with heat transfer: Application to biomedicine. Nonlinear Eng. 2019, 8, 619-629. [CrossRef]

48. Maqbool, K.; Mann, A.B.; Siddiqui, A.M.; Shaheen, S. Fractional generalized Burgers' fluid flow due to metachronal waves of cilia in an inclined tube. Adv. Mech. Eng. 2017, 9, 1687814017715565. [CrossRef]

49. Akbar, N.S.; Tripathi, D.; Khan, Z.H.; Beg, O.A. Mathematical model for ciliary induced transport in MHD flow of $\mathrm{Cu} / \mathrm{H}_{2} \mathrm{O}$ nanofluids with magnetic induction. Chin. J. Phys. 2017, 55, 947-962. [CrossRef]

50. Nadeem, S.; Sadaf, H. Trapping study of nanofluids in an annulus with cilia. AIP Adv. 2015, 5, 127204. [CrossRef]

(C) 2020 by the authors. Licensee MDPI, Basel, Switzerland. This article is an open access article distributed under the terms and conditions of the Creative Commons Attribution (CC BY) license (http://creativecommons.org/licenses/by/4.0/). 